San Jose State University

SJSU ScholarWorks

Mineta Transportation Institute Publications

$9-2020$

\title{
Altamont Pass Commuter Study: A Longitudinal Analysis of Perceptions and Behavior Change
}

Orestis Panagopoulos

California State University, Stanislaus

Gökçe Soydemir

California State University, Stanislaus

Xun Xu

California State University, Stanislaus

Follow this and additional works at: https://scholarworks.sjsu.edu/mti_publications

Part of the Transportation Commons

\section{Recommended Citation}

Orestis Panagopoulos, Gökçe Soydemir, and Xun Xu. "Altamont Pass Commuter Study: A Longitudinal Analysis of Perceptions and Behavior Change" Mineta Transportation Institute Publications (2020). https://doi.org/10.31979/mti.2020.1917

This Report is brought to you for free and open access by SJSU ScholarWorks. It has been accepted for inclusion in Mineta Transportation Institute Publications by an authorized administrator of SJSU ScholarWorks. For more information, please contact scholarworks@sjsu.edu. 


\section{SJSU SAN SOSES STARE

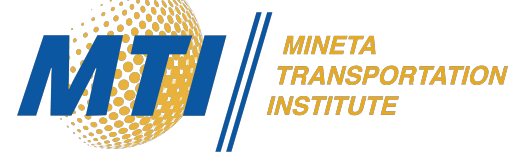

Altamont Pass Commuter Study: A Longitudinal Analysis of Perceptions and Behavior Change

Orestis Panagopoulos, PhD

Gökçe Soydemir, PhD

$\mathrm{Xun} \mathrm{Xu}, \mathrm{PhD}$

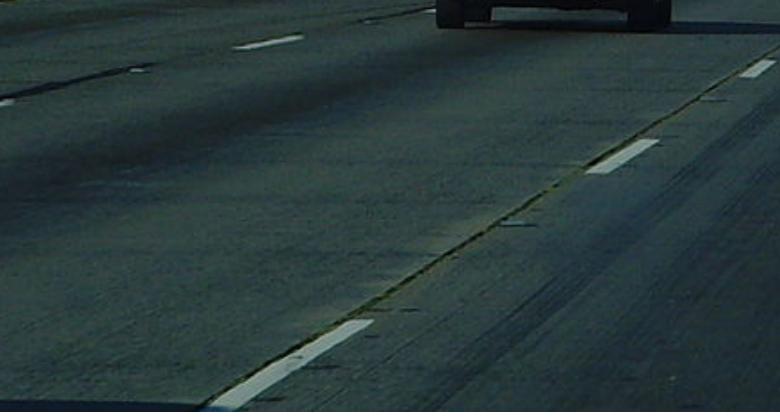




\section{Mineta Transportation Institute}

Founded in 1991, the Mineta Transportation Institute (MTI), an organized research and training unit in partnership with the Lucas College and Graduate School of Business at San José State University (SJSU), increases mobility for all by improving the safety, efficiency, accessibility, and convenience of our nation's transportation system. Through research, education, workforce development, and technology transfer, we help create a connected world. MTI leads the Mineta Consortium for Transportation Mobility (MCTM) funded by the U.S. Department of Transportation and the California State University Transportation Consortium (CSUTC) funded by the State of California through Senate Bill 1.

MTI focuses on three primary responsibilities:

\section{Research}

MTI conducts multi-disciplinary research focused on surface transportation that contributes to effective decision making. Research areas include: active transportation; planning and policy; security and counterterrorism; sustainable transportation and land use; transit and passenger rail; transportation engineering; transportation finance; transportation technology; and workforce and labor. MTI research publications undergo expert peer review to ensure the quality of the research.

\section{Education}

To ensure the efficient movement of people and products, we must prepare a new cohort of transportation professionals who are ready to lead a more diverse, inclusive, and equitable transportation industry. To help achieve this, MTI sponsors a suite of workforce development and education opportunities. The Institute supports educational programs offered by the Lucas Graduate School of Business: a Master of
Science in Transportation Management, plus graduate certificates that include High-Speed and Intercity Rail Management and Transportation Security Management. These flexible programs offer live online classes so that working transportation professionals can pursue an advanced degree regardless of their location.

\section{Information and Technology Transfer}

MTI utilizes a diverse array of dissemination methods and media to ensure research results reach those responsible for managing change. These methods include publication, seminars, workshops, websites, social media, webinars, and other technology transfer mechanisms. Additionally, MTI promotes the availability of completed research to professional organizations and works to integrate the research findings into the graduate education program. MTI's extensive collection of transportation-related publications is integrated into San José State University's world-class Martin Luther King, Jr. Library.

\section{Disclaimer}

The contents of this report reflect the views of the authors, who are responsible for the facts and accuracy of the information presented herein. This document is disseminated in the interest of information exchange. MTI's research is funded, partially or entirely, by grants from the U.S. Department of Transportation, the U.S. Department of Homeland Security, the State of California, and the California Department of Transportation, whom assume no liability for the contents or use thereof. This report does not constitute a standard specification, design standard, or regulation. 
Report 20-43

\title{
Altamont Pass Commuter Study: A Longitudinal Analysis of Perceptions and Behavior Change
}

\author{
Orestis Panagopoulos, $\mathrm{PhD}$ \\ Gökçe Soydemir, $\mathrm{PhD}$ \\ $\mathrm{Xun} \mathrm{Xu}, \mathrm{PhD}$
}

September 2020

A publication of the

Mineta Transportation

Institute

Created by Congress in 1991

College of Business

San José State University

San José, CA 95192-0219 


\section{TECHNICAL REPORT DOCUMENTATION PAGE}

\begin{tabular}{|c|c|c|c|}
\hline $\begin{array}{l}\text { 1. Report No. } \\
20-43\end{array}$ & 2. Government Accession No. & \multicolumn{2}{|c|}{ 3. Recipient's Catalog No. } \\
\hline \multicolumn{2}{|l|}{ 4. Title and Subtitle } & $\begin{array}{l}\text { 5. Report Date } \\
\text { September } 2\end{array}$ & \\
\hline \multicolumn{2}{|c|}{$\begin{array}{l}\text { Altamont Pass Commuter Study: A Longitudinal Analysis of Perceptions and } \\
\text { Behavior Change }\end{array}$} & \multicolumn{2}{|c|}{ 6. Performing Organization Code } \\
\hline \multicolumn{2}{|c|}{$\begin{array}{l}\text { 7. Authors } \\
\text { Orestis Panagopoulos, PhD Gökçe Soydemir, PhD Xun Xu, PhD }\end{array}$} & \multicolumn{2}{|c|}{$\begin{array}{l}\text { 8. Performing Organization } \\
\text { Report } \\
\text { CA-MTI-1917 }\end{array}$} \\
\hline \multirow{2}{*}{\multicolumn{2}{|c|}{$\begin{array}{l}\text { 9. Performing Organization Name and Address } \\
\text { Mineta Transportation Institute } \\
\text { College of Business } \\
\text { San José State University } \\
\text { San José, CA 95192-0219 }\end{array}$}} & \multicolumn{2}{|c|}{ 10. Work Unit No. } \\
\hline & & \multicolumn{2}{|c|}{$\begin{array}{l}\text { 11. Contract or Grant No. } \\
\text { ZSB12017-SJAUX }\end{array}$} \\
\hline \multirow{2}{*}{\multicolumn{2}{|c|}{$\begin{array}{l}\text { 12. Sponsoring Agency Name and Address } \\
\text { State of California SB1 2017/2018 } \\
\text { Trustees of the California StateUniversity } \\
\text { Sponsored Programs Administration } \\
401 \text { Golden Shore, } 5^{\text {th }} \\
\text { Long Beach, CA } 90802\end{array}$}} & \multicolumn{2}{|c|}{$\begin{array}{l}\text { 13. Type of Report and Period } \\
\text { Covered } \\
\quad \text { Final Report }\end{array}$} \\
\hline & & \multicolumn{2}{|c|}{ 14. Sponsoring Agency Code } \\
\hline \multicolumn{4}{|l|}{$\begin{array}{l}\text { 15. Supplemental Notes } \\
\text { DOI: } 10.31979 / \mathrm{mti} .2020 .1917\end{array}$} \\
\hline \multicolumn{4}{|l|}{ 16. Abstract } \\
\hline \multicolumn{4}{|c|}{$\begin{array}{l}\text { The Altamont Pass commuter survey study examines commuters' perceptions and behaviors towards public } \\
\text { transportation during 2019-2020. Results are compared with surveys conducted in } 2000 \text { and } 2006 \text { to investigate } \\
\text { whether there have been any longitudinal changes in the perceptions and behaviors of Altamont Pass commuters over } \\
\text { the twenty-year interval. As the previous surveys do, this study focuses on the same three counties, namely, San } \\
\text { Joaquin, Stanislaus, and Merced that comprise the Northern San Joaquin Valley (NSJV). When compared with the } \\
\text { previous surveys, these findings reveal some significant differences of responses to most questions, and minor } \\
\text { differences of responses to other questions, prompting several important conclusions. }\end{array}$} \\
\hline \multicolumn{4}{|c|}{$\begin{array}{l}\text { Based on the survey responses received, the authors categorize several immediate, short-run, and long-run } \\
\text { improvements that can be made in the existing transportation network to alleviate congestion and smooth flow of } \\
\text { traffic through the freeways and local public transportation network. }\end{array}$} \\
\hline $\begin{array}{l}\text { 17. Key Words } \\
\text { commuter, survey, Northern San } \\
\text { Joaquin Valley, Altamont Pass, } \\
\text { questionnaire }\end{array}$ & $\begin{array}{l}\text { 18. Distribution Statement } \\
\text { No restrictions. This document is } \\
\text { public through The National Tech } \\
\text { Service, Springfield, VA } 22161\end{array}$ & $\begin{array}{l}\text { lable to the } \\
\text { al Information }\end{array}$ & \\
\hline $\begin{array}{l}\text { 19. Security Classif. (of this report) } \\
\text { Unclassified }\end{array}$ & $\begin{array}{l}\text { 20. Security Classif. (of this page) } \\
\text { Unclassified }\end{array}$ & $\begin{array}{l}\text { 21. No. of Pages } \\
46\end{array}$ & 22. Price \\
\hline
\end{tabular}

Form DOT F 1700.7 (8-72) 


\section{Copyright (C) 2020 \\ by Mineta Transportation Institute \\ All rights reserved.}

DOI: $10.31979 / \mathrm{mti} .2020 .1917$

Mineta Transportation Institute College of Business

San José State University San José, CA 95192-0219

Tel: (408) 924-7560

Fax: (408) 924-7565

Email: mineta-institute@sjsu.edu

transweb.sjsu.edu/research/1917 


\section{ACKNOWLEDGMENTS}

We would like to acknowledge our student assistants Margaret Creighton, Andrew Kennedy, and Esther Massawi for their work in survey collection and data entry. We would also like to acknowledge Kim Anderson and Yvette Davis for writing a letter of support and in their leading role as officials from the San Joaquin County of Government. 


\section{CONTENTS}

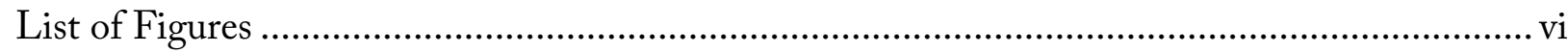

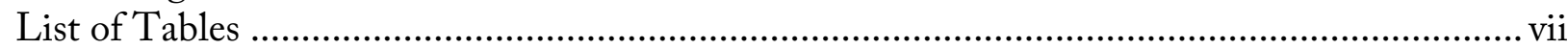

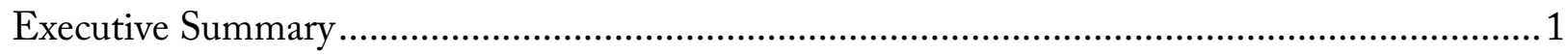

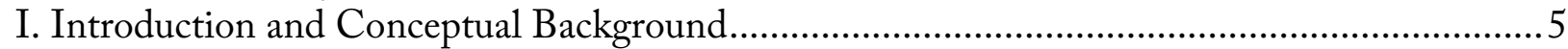

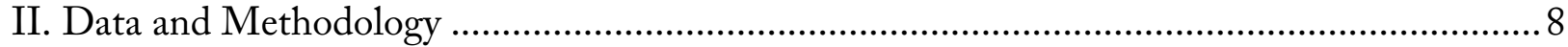

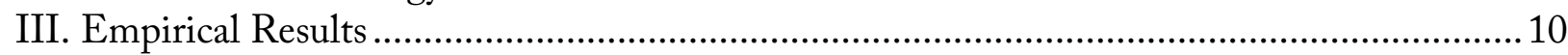

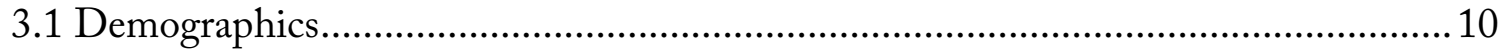

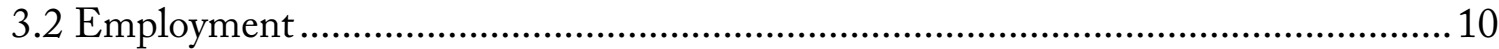

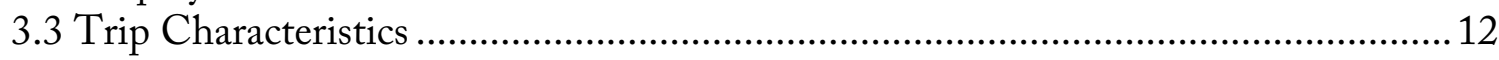

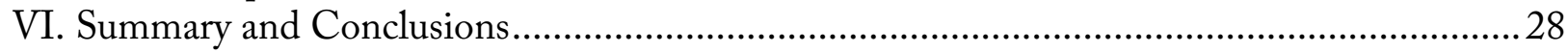

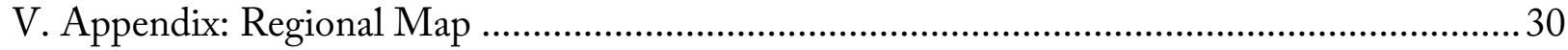

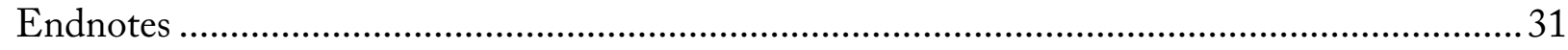

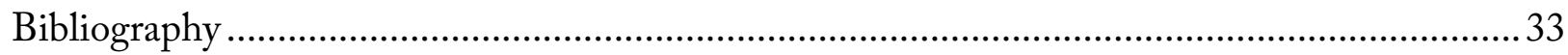

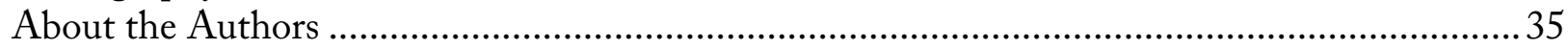




\section{LIST OF FIGURES}

Figure 1. Years at Current Residence vs. Commute Time ..................................................... 15

Figure 2. Years at Current Employer vs. Commute Time ....................................................24

Figure 3. Age vs. Commute Time ................................................................................ 25

Figure 4. Hourly Salary vs. Commute Time ....................................................................... 26 


\section{LIST OF TABLES}

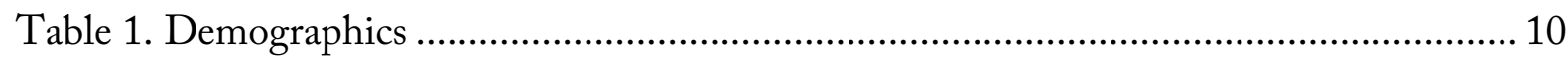

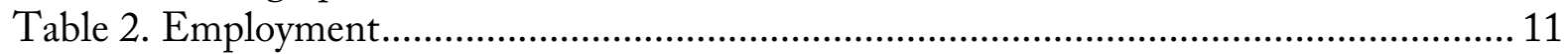

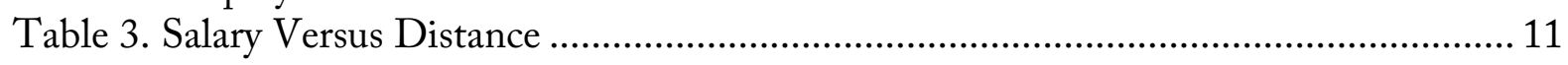

Table 4. How long have you worked for your current employer? ..................................... 12

Table 5. Point of Origin .......................................................................................... 13

Table 6. Top Cities of Point of Destination ....................................................................... 13

Table 7. Duration of Trip per Point of Destination Overall ............................................ 14

Table 8. Duration of Trip per Point of Destination by Bus ............................................ 16

Table 9. Duration of Trip per Point of Destination-Train Riders.................................. 17

Table 10. Responses to the Question: Which of the following would encourage you to switch

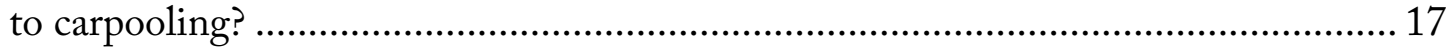

Table 11. Responses to the Question: What would encourage you to ride the bus or the ACE

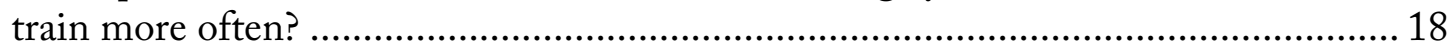

Table 12. Selected Responses to the Open-Ended Question: Please express your opinion(s) below on how to further improve commuting over Altamont Pass. .......................... 18

Table 13. Educational Attainment of Respondents Answering the Question: Which of the following would encourage you to switch to carpooling?.......................................2 27

Table 14. Average Weekly Salary of the Respondents Answering the Question: Which of the following would encourage you to switch to carpooling?.......................................2 27

Table 15. Average Commute Time Based the Question: Which of the following would encourage you to switch to carpooling? ............................................................ 28 


\section{Executive Summary}

In this commuter survey study, we examine the perceptions and behaviors of Altamont Pass commuters towards public transportation. We compare our results with the surveys done in $2000^{1}$ and $2006^{2}$ to investigate whether there have been any longitudinal changes in commuter perceptions and behavior of Altamont Pass commuters over a twenty-year interval. As the previous surveys do, our study focuses on the same three counties, namely, San Joaquin, Stanislaus and Merced that comprise the Northern San Joaquin Valley (NSJV). When compared with the previous surveys, our findings reveal some significant differences of responses to most questions and minor differences of responses to other questions, allowing us to draw several important conclusions.

Based on the responses received in our survey we categorize several immediate, short-run, and long-run improvements that can be made in the existing transportation network to alleviate congestion and smooth flowing of traffic through the freeways and local public transportation network. In particular, survey respondents from our study report an assessment value of 2.19 (43.8\%) out of a 5.0 points scale (from 1 being least satisfied to 5 being most satisfied) in terms of their satisfaction of the current system in place. Commuters in our survey also rate their job satisfaction as 3.74 out of 5.0 scale (74.8\%) (from a value of 1 being least satisfied to 5 being most satisfied).

Demographic attributes show that female commuters have continued to increase over the twentyyear interval. The percentage of commuters 45 years or older decreased in our present 2019-20 survey relative to the 2006 survey. Those commuters who had a bachelor's degree or higher continued to increase in our 2019-20 survey by about the same increment as in 2006. Employment characteristics display little change in 2019-20 survey when compared with 2000 and 2006 surveys. Administrative and support services continued to be the most selected category in 2019-20 survey which was also the most selected in 2000 and 2006 surveys. However, the second most selected commuter category of employment in our present 2019-20 survey was computers which was the third most selected category in 2000 and 2006 surveys. Interestingly, construction was the second most selected in the 2000 and 2006 survey, consistent with the inventory shortage view that construction employees are now building more homes in the NJSV and tend to avoid commuting relative to previous years.

We find that the factors influencing commuters' choice toward the Altamont Corridor Express (ACE) train, smart bus, Bay Area Rapid Transit (BART), or a combination of those transportation modes between the NSJV to Bay Area vary widely. Among those that are most noteworthy is city of residence, income, and number of car poolers residing close to home and work. Several respondents take a combination, such as those living in cities such as Turlock, Tracy and Livermore, where they take a bus to BART and then continue their commute using BART. These respondents also report a strong desire to extend BART to Tracy and ACE to Merced. Those commuters who use BART request squeezing more trains in between the existing run 
schedules. These commuters also want free high-speed internet service on board and snack machines to improve their productivity and efficiency of travel during commute hours. They also request more comfortable seating and more space to place their bicycles in trains.

Solo drivers report a willingness to switch to another mode of transportation such as a vanpool, carpool, express bus, or train if they are offered cash incentives and tax breaks. In contrast to the previous survey results, an overwhelming majority of respondents report they would settle for same or slightly higher wages, not lower wages, if they found similar jobs in NSJV. The type of jobs reported are predominantly in high-skilled jobs in information technology, business-related, and health care. Consequently, the type of jobs that would have to come to the NSJV to alleviate commuting likely would be in the same fields.

As an immediate solution, a significant number of respondents want some degree of limitation of heavy trucks and semi-trucks from getting on freeways during rush hour traffic similar to restrictions that are now in place from north of 238 freeway to Oakland. These respondents believe lives would be saved and fatalities and injuries would decline from having fewer accidents on roads, and greater efficiency would be attained resulting from a decrease in travel time and fuel savings due to relatively less congestion. Our calculations reveal that limiting trucks during rush hour would save about 30 percent space on roads, equivalent to adding one extra lane, which would have significant impact in terms of alleviating congestion. Further, because most truck drivers get paid based on miles driven, being stuck in during rush hour traffic would also mean loss of efficiency for them in terms of fuel consumption, payment based on miles driven, and greater stress from being stuck in traffic while driving. A reallocation between driving and break time on the part of truckers would save time for truck drivers as well. Respondents want limitation of heavy truck traffic during rush hour by way of incentives or restrictions placed on heavy truck traffic on NSJV portions of 99 and 580 freeways.

Trip characteristics changed little in 2019-20 survey from previous surveys results. San Joaquin County continued to be the top point of origin in the three surveys, followed by Stanislaus Country. However, the percentage of commuters from San Joaquin County dropped from 71.2 percent in 2000 to 61.1 percent in the 2019-20 survey. Stanislaus County increased from 23.2 percent to 27.3 percent. Merced also increased from 0.8 percent to 2.5 percent. Some commuters began commuting against the traffic. Alameda commuters increased from 0.9 percent in 2000 to 6.5 percent in the present 2019-20 survey.

On the other hand, top cities of destination changed very little in 2019-20 from the previous two surveys done in 2006 and 2000. Alameda was the top county of destination, but the percentage decreased from 69.8 percent in 2006 to 51.8 percent in 2019. Santa Clara was the second top county of destination with 15.0 percent reported in 2006 to 22.3 percent reported in 2019. Big change occurred in the third top county of destination switching from Contra Costa County in 2006 to San Francisco County in 2019-20 survey. 
Overall trip duration of sole drivers decreased by about ten minutes from 1.37 hours in 2006 to 1.26 hours in 2019-20 survey. Average time to commute by bus increased from 1.41 hours to 2.08 hours in 2000 and 2006 respectively, perhaps due to the increase in the number of bus stops over the same time interval. The average time it takes to commute by train was 2.09 hours in 2019-20 changing very little from 2000 which was 2.01 hours. The association between length at current residence and the time it takes the commute became more downward sloping, pointing to some improvement in commute over the last decade. The association between age and commute time was positive, indicating that as age increases so does commute time. When the association between commute time and years at work was tested, a negative association was found in that the more time a commuter spends at current workplace, the lower the commute time of the respondent. Only 10.8 percent of commuters reported telecommuting at least one day in 2000 . This percentage increased very significantly in 2019-20 survey to 64.8 percent. A lot more respondents chose cash incentives (41.33 percent) than tax breaks (17.07 percent) in 2019-20 as a factor that would switch them to carpooling. "Less expensive train fares" was the response selected most in the survey that would encourage respondents to riding bus or ACE train more often, followed by more flexible hours. Most reported that the train schedules were not in sync with their work schedules and cited this as a major impediment to riding bus or ACE train more often.

New technology positively affects commuters' change of behavior towards public transportation. Among the most important ones are faster trains, longer service hours, providing charging ports on trains, more ergonomic seating, and food service. Overall, the results show that general perceptions toward public transportation mode have changed quite notably in recent years. Commuters express a strong desire for ACE to extend to Turlock and Merced, expressway to extend to Tracy.

Out of pocket costs in the 2000 surveys pertain to parking fees, transit fares, vanpool expense, total driver costs, and composite commuter costs. The average parking fee reported in the 2000 survey was $\$ 7.14$ per day. In the 2019-20 survey, the out of pocket fee expense increased to $\$ 18.77$ per day. Considering the increases in the overall price levels and real estate, this number appears to be consistent. Further, the overall increase in wages have been around 42 percent. When this is change is factored in the account, it becomes apparent that parking fees have increased more than wages over the twenty-year interval. In the 2000 survey bus riders paid on average $\$ 6.15$ per day in fares, while train riders and BART riders spent $\$ 11.04$ and $\$ 9.11$ respectively. The respondents in the 2019-20 survey reported a combined average out-of-pocket cost of $\$ 16.94$ per day. When this fare is compared with the combined average cost of $\$ 8.76$ in the 2000 survey, there appears to be a two-fold increase over a period of two decades. This finding appears to be consistent with rate of inflation and wage increases over the same interval, being slightly higher than the two measures of purchasing power. Vanpoolers reported average expenses of $\$ 9.52$ per day in the year 2000 survey. Respondents in the 2019-20 survey reported an average vanpool expense of $\$ 18.43$ per day. This finding is also consistent and little above the inflation rate and wage increase over the twenty-year interval. 
In all findings provide important policy implications for government officials and private citizens in terms of new strategies to pursue in alleviating problems associated with commuting over the Altamont Pass in the next decade. 


\section{Introduction and Conceptual Background}

The Northern San Joaquin Valley floor and foothills rising to the Sierra Nevada Mountains is beautiful country. Unfortunately, this pristine landscape of great tourist attraction is one of the poorest regions in the United States in terms of per capita income and human capital. The unemployment rates in the region are much higher than that of California and the nation as a whole. The labor force growth has been very gradual since the end of the Great Recession, only to register a faster pace in the last several years. The ratio of unskilled to skilled labor force is also much higher than other regions of California and the nation.

Limited by the oceans in the west, California economy can only expand eastward. However, the inland region deeply lacks sufficient infrastructure currently, including transportation to sustain such growth. Given the current setting, the purpose of this study is to examine the transportation needs of the Northern San Joaquin Valley (NSJV) economy. The study conducts a commuter survey directly comparable to the previous ones (Billheimer \& McNally, 2006; San Joaquin Council of Governments, 2006; Yosemite Computer Consultants \& Wright, 2003). In doing so, this study provides an assessment of transportation demand and commuters' perceptions and behavior change in NSJV by drawing a comparison to the surveys conducted in 2006 and 2000.

We make several unique contributions to the extant literature of transportation needs of the California economy. First, with increased employment levels, housing needs, and living expenses in the San Francisco Bay Area, many people live in the Northern San Joaquin Valley and commute. However, other than the surveys that were conducted in 2000 and 2006, no recent comparable study exists that extensively surveys commuting patterns of such residents. Second, we investigate whether there is any change in the way commuters perceive public transportation and display any change in behavior in terms of their preference towards public transportation between NSJV and the Bay Area. Thus, the study explores NSJV residents' needs, expectations, and perceptions with the goal to improve the choices regarding public transportation, travel time, and cost of commuting. Lastly, based on the responses received the study offers three solutions. These three solutions are categorized into immediate, short-run, and long-run solutions to alleviate congestion during rush hours over the Altamont Pass that would improve time and money cost and save lives and injuries by decreasing the number of accidents resulting from heavy traffic. ${ }^{3}$

The study focuses on the impacted area that formally comprises three counties of Northern San Joaquin Valley: San Joaquin, Stanislaus, and Merced. Data is aggregated from these regions to investigate the overall and individual impact on the regional economy as represented by these three counties. ${ }^{4}$ According to a recent study ${ }^{5}$ the cities of Stockton and Modesto have the highest percentage in the nation of residents driving $90+$ minutes to work each day. A commuter who is using private mode of transportation, say starting the commute from Modesto, would first have to get on freeway 99 and then merge into highway 120. After merging on highway 120, the commuter would then have to go on to the Interstate 5 freeway for short while before merging into freeway 205. Freeway 205 then merges into freeway 580 which goes through Altamont Pass. Then the 
commuter would go northbound on freeway 580 which merges into freeway 80 to pass through the Bay Bridge and finalize the trip in downtown San Francisco.

Many studies have examined commuter satisfaction and behavior change in the extant literature. There appears to be a lack of generalizability from recent extant studies and surveys conducted outside the NSJV but in similar contexts. One such study that comes somewhat close to our study analyzes workplace attachment and commuter satisfaction before and after workplace relocation in Montreal, Canada. Using a multinomial logit analysis, the researchers found that changes in travel time is associated with evolving commuter satisfaction ${ }^{6}$. Another survey study examines the relationship between financial incentives provided by employers and commuters' decisions to use transit in Atlanta region. They find that encouraging local employers to offer a free or subsidized transit pass instead of free or subsidized parking to their employees would be an effective strategy to manage transportation or travel demand in the region ${ }^{7}$. Studies also find how commuting behavior changes due to incentives in the Beijing subway system. Previous survey results reveal that providing incentives such as fast food restaurant related services and reduced ticket fares have a positive influence in avoiding the morning rush hour. Other factors associated with commuting behavior change in Beijing are discounts on wireless services, flexible work schedules, and a more efficient subway system ${ }^{8}$. Researchers investigated commuter satisfaction and travel time in the Korean city Gyeonggi. Using a binomial logit model, they found that the association between commuter satisfaction and travel time is not linear but $\mathrm{V}$-shaped, which points to other factors at play such as perceived neighbor quality and socioeconomic characteristics, individual attitudes, and job-related characteristics ${ }^{9}$. Scholars discuss commuter benefit programs and mode choice from the 2014 Puget Sound Regional Travel Survey. The outcome is that that employer sponsored parking benefits, and transit subsidies end up spilling over to non-commute trips as well as to other members in the same household ${ }^{10}$. In another study, it was revealed that carpooling average wait times were shorter when compared to other travel modes such as Bus/BART, with median wait times less than 2.5 minutes for riders and two minutes for drivers ${ }^{11}$. Three out of four commuters were formerly public transit riders. Our study is unique in that, in conducting a new survey, we draw a direct comparison from prior surveys to see how commuter behavior changes longitudinally.

Our key research questions attempt to capture a longitudinal comparison of several socioeconomic variables related to commuting over Altamont Pass. The comparisons done in our survey with the surveys done in the prior years are demographics, trends in employment, trip characteristics, and drivers' change in commuting related perceptions.

In particular, the current study examines which types of transportation improvements would bring the most economic benefit to the San Joaquin Valley. Further, the study examines solo drivers' perceptions in choosing another mode of transportation such as vanpool, carpool, express bus, or train. The study considers the types of jobs that would need to come to the valley to bring commuting to a minimal level. The study also investigates the extent to which recent changes in the economic landscape impact transportation perceptions and behavior change as they relate to public transportation. 
We find that, since 2006, NSJV's population influx has resulted in a significant change of perceptions on commuting demand and public transportation of some areas and some minimal to no change in other areas. Further, survey responses reveal that several new incentives and disincentives can be applied to increase the use of public transportation modes. There are a few factors that come out of the surveys influencing commuters' choice of transportation mode commuting between NSJV and Bay Area such as hours of operation, amenities provided in public transportation vehicles, as well as demands to increase service areas into Merced and Madera.

Survey respondents report an assessment value of 2.19 (43.8\%) out of a 5-point scale, from 1 being least satisfied to 5 being most satisfied. This scale rates commuters' satisfaction level in terms of their choice of private transportation mode and their perceptions toward the state routes, interstate highways, and city roads. Commuters' rating of their current level of job satisfaction on a scale of 5.0 points averages out to 3.74 (74.8\%), from a value of 1 being least satisfied to 5 being most satisfied.

We find that the factors influencing commuters' choice toward the ACE train, smart bus, BART, or a combination of those transportation modes from the NSJV to Bay Area varies widely in the 2019-20 survey. ${ }^{12}$ Among those that are most noteworthy include city of residence, income, and number of car poolers residing close to home and work. Several respondents take a combination of modes, such as those living in cities such as Turlock, Tracy, and Livermore where they take a bus to BART and then continue their commute using BART. These respondents also report a strong desire to extend BART to Tracy and ACE to Merced. Those that use BART request having a free high-speed internet service on board and snack machines to improve their productivity and comfort of travel during commute hours. They also request more comfortable seating and squeezing in more trains between existing service schedules.

Solo drivers report a willingness to switch to another mode of transportation such as vanpool, carpool, express bus, or train if they are offered cash incentives and tax breaks. In contrast to the previous survey results, an overwhelming majority of respondents report they would settle for same wages if they found similar jobs in NSJV while others, similar to past surveys, report settling for higher wages. The type of jobs reported are predominantly in high skilled jobs in information technology, business related, and health care. Consequently, the type of jobs that would have to come to the NSJV to alleviate commuting needs would be in the same fields.

New technology positively affects commuters' behavior change towards public transportation. Among the most important new technologies are faster trains, longer service hours, providing internet services on trains, more ergonomic seating, and smart vending machines. Overall, the results show that general perceptions toward public transportation have changed quite notably in recent years. Commuters express a strong desire for ACE to extend to Turlock and Merced, and for the expressway to extend to Tracy. 
The remainder of the study is organized as follows. Section two describes data and statistics. Section three reviews literature and summarizes the methodology used in the study. Section four reports empirical results. Section five concludes.

\section{Data and Methodology}

The survey respondents are composed of a California NSJV cohort. In particular, this cohort encompasses the residents of San Joaquin, Stanislaus, and Merced counties who commute to the Bay Area through Altamont Pass. We used the San Joaquin County Government database, which contains these three counties' residents' contact information to which the surveys were sent by email. The San Joaquin County Government database does not include all the residents from the three-county region. Their sampling method is based on those residents who have responded to previous surveys and communications and those who have chosen to subscribe and become a member of their reach-out efforts, "Dibs", to promote smart travel, sharing by way of vanpooling, and riding transit from their website www.dibsmyway.com. The objective of Dibs is to offer the tools and resources to make commuting easy and accessible for the public and at the same make the public aware of their transportation options. Additionally, surveys were distributed by hand at several of the region's bus stops and train stations, with distributors asking commuters to fill out hardcopy surveys. The survey was also distributed to Stan State students, faculty, and staff who commute over Altamont Pass and were instructed to fill out the survey only if they commuted.

After deleting unused and obsolete accounts, the effective sample size of about six thousand Altamont Pass commuters was comparable to the previous surveys done in 2006 and 2000. The sample response rate of 534 is roughly in the ten percent range, about the same rate as the previous surveys.

The survey was conducted during the period of October 2019 to January 2020. The participants had more than four months to respond and reminders were sent to them to increase the response rate. We used questions from the two previous surveys done in 2006 and 2000, and also incorporated the research questions mentioned earlier to reflect the current commuters' status. By doing so, we followed the structure of the aforementioned surveys, so they are comparable. At the same time we were able to get a more in-depth understanding of commuters' perceptions. Our survey consists of twenty-eight questions of various types such as: closed-ended questions, multiple choice questions, Likert-scale questions, rating questions, and open-ended questions. The participants could use any form of electronic device to complete the digital survey such as personal computers, smartphones, and tablets. The paper surveys were collected as soon as participants filled them out. These responses were transformed into digital ones and then inputted into Qualtrics (Snow \& Mann, 2013). 
The aggregated responses were exported into a comma-separated values file for further processing and analysis. The integrity of the responses was evaluated first. Any invalid inputs were removed. Then the dataset was checked for missing data. Missing values that could be inferred from neighboring answers were imputed. For example, when a responder provided a zip code the city/town could be inferred and vice versa.

Upon analyzing the responses we received, several outliers were detected that had the potential of biasing the results. One such outlier issue was observed in the reported commute times. Several respondents reported six and five hours of commute to the Bay Area. The question asked the commute one way from the origin to the destination. Considering that six and even five hours commute in one direction would be unrealistic and, even in the worst case scenario, extremely rare, we assumed these resulted from misinterpreting the question. Therefore these outliers which were more than several standard deviations from the mean were eliminated from the analysis.

We used Microsoft Excel and SPSS ${ }^{13}$ to calculate descriptive statistics that were used to populate the presented tables of this study. We also used several econometric software packages such as RATS $^{14}$, EViews ${ }^{15}$ to carry out regression analyses on the responses collected (Doan, 1988). Before running regression analyses, we made sure the data was transformed into a continuous format to obtain robust results. The regression method we chose for this part was ordinary least squares. Logit and probit models were used whenever data are binary and discontinuous in nature. All tables were designed on Microsoft Word.

In addition to comparing data to the previous two surveys, some of the data was used to carry out additional analyses addressed only by the 2019-20 survey to constitute a basis of comparison for other studies to be done in the future. These analyses investigate new research questions such as if there is an association between commute time, time spent on current occupation, and age dispersion among the commuters. The purpose is to see whether in the future an increase in aging of the commuter population corresponds to a lower or higher average commuting time like the one found in this study. Similarly, the purpose in examining the time spent at work and commute time was to see whether in the future the association is higher when compared with this study which would, among other things, point to finding better ways to commute than in the past. The qualitative and quantitative sections from the open-ended responses and statistical analyses of our investigation fit together by providing an additional check for consistency from different angles, bringing an added dimension for comparisons with prior surveys. 


\section{Empirical Results}

\subsection{Demographics}

Demographic characteristics we analyze include questions such as age, gender, marital status, education level, length of current residence, and home ownership. We aim to compare characteristics such as demographics, employment, salary vs. distance, point of origin, and point of destination from our study with the common ones from 2000 and 2006 surveys.

Table 1 reports a comparison of results of demographics from surveys conducted in the years 2000, 2006, and our 2019-20 survey. In the 2006 survey, the number of female commuters increased slightly from 2000 while the number of male commuters decreased. In our survey, all $62.8 \%$ of the corridor users were male, while $37.1 \%$ were female. Of the total commuters, $53.8 \%$ were 45 years old or older. Whereas in 2000, 64.9\% of Altamont Pass commuters were men and 35.3\% were female. The percentage of people that were 45 -years-old or older was also lower. This trend continued in 2019 during which male commuters continued to decrease while female commuters continued to increase, but the incremental increase in 2019 was larger than that of 2006. Of the total commuters in 2019-20 survey, 32.12 percent were 45 years of age or older.

Table 1. Demographics

\begin{tabular}{cccc}
\hline Demographics & 2000 & 2006 & 2019 \\
\hline Male & $64.9 \%$ & $62.8 \%$ & $45.51 \%$ \\
Female & $35.1 \%$ & $37.1 \%$ & $54.49 \%$ \\
45 years old or older & $36.5 \%$ & $53.8 \%$ & $32.12 \%$ \\
Has bachelor's degree or higher & $23.2 \%$ & $30.8 \%$ & $38.21 \%$ \\
\hline
\end{tabular}

The 2000 survey showed that $23.2 \%$ of drivers on the corridor had a bachelor's degree or higher. In 2006 that number increased to $30.8 \%$. There was about the same incremental increase of about seven to eight percentage points of those commuters with a bachelor's degree or higher in 2019-20 survey when compared with the 2006 survey.

\subsection{Employment}

Table 2 reports employment categories from the three surveys conducted. In the 2006 survey, respondents were provided with a list of occupations and asked to select the entry that best described their current occupation. The occupation selected most often by the respondents was the generic category of "Administration/Support Service." Some main categories identified by the 
Altamont Pass commuters in 2006 are listed below along with the corresponding data from the 2000 survey. The same category of employment is the most often selected in 2019 as well, followed by the "Computers" category which happened to be the third category in the 2006 survey.

Table 2. Employment

\begin{tabular}{cccc}
\hline Top Occupations & 2000 & 2006 & 2019 \\
\hline Administration/Support Service & $11.8 \%$ & $8.7 \%$ & $9.17 \%$ \\
Construction & $11.0 \%$ & $7.2 \%$ & $3.88 \%$ \\
Computers & $10.3 \%$ & $4.5 \%$ & $5.82 \%$ \\
Manufacturing & $10.0 \%$ & $7.0 \%$ & $3.53 \%$ \\
Engineering & $7.8 \%$ & $5.3 \%$ & $3.17 \%$ \\
\hline
\end{tabular}

Table 3 reports responses to the question, "in order to work closer to home, what salary level would you require?", asked in all of three surveys. There were significant differences between 2019-20 survey and the two surveys done in prior years. In particular, there is a significant drop in those respondents who selected slightly lower salary in 2019. In contrast, the increase in those respondents who selected more than current salary in 2019 was significantly higher coming in second place. "Slightly lower salary" had come in second after "current salary" in the surveys reported in years 2000 and 2006.

Table 3. Salary Versus Distance

\begin{tabular}{cccc}
\hline Work Closer to Home & 2000 & 2006 & 2019 \\
\hline Slightly lower salary & $25.9 \%$ & $29.5 \%$ & $15.60 \%$ \\
Current salary & $63.1 \%$ & $59.4 \%$ & $49.62 \%$ \\
More than current salary & $10.0 \%$ & $8.4 \%$ & $34.78 \%$ \\
\hline
\end{tabular}

"Current salary" selection consistently fell as a percentage from 2000 to 2019. Further, there was about a ten percent decline in the 2019-20 survey in the number of respondents who chose the "current salary" option when compared to the survey from 2006. In the 2019-20 survey, 75.74 percent of respondents reported that they do not hold a management/supervisory position, while the remaining 24.26 percent reported holding a management/supervisory position. In an average work week, respondents reported 2.01 days a week of work at home.

Table 4 reports responses from the 2019-20 survey to the question, "how long have you worked for your current employer?" The respondents that reported having worked less than one year 
constituted 21.71 percent while those that reported working at least one but less than three years were 25.01 percent of the sample. The respondents that reported at least three but less than five years with current employer amounted to 14.48 percent and those that reported at least five but less than ten years was 13.37 percent. Both cohorts constituted the lowest number of commuters while the cohort with ten or years with current employer had the highest percentage of commuters using the Altamont Pass. Further, those respondents that reported not owning a home made up 53.21 percent of the sample; the remaining 46.79 percent reported owning their home in the 201920 survey. This was a significant drop from the 2000 survey in which reported home ownership was 83 percent.

Table 4. How long have you worked for your current employer?

\begin{tabular}{lc}
\hline Response & $2019-20$ \\
\hline Less than one year & $21.71 \%$ \\
At least one but less than three years & $25.01 \%$ \\
At least three but less than five years & $14.48 \%$ \\
At least five but less than ten years & $13.37 \%$ \\
Ten or more years & $25.43 \%$ \\
\hline
\end{tabular}

The average number of years lived in current residence was 9.23 years in the 2019-20 survey which was about five years higher than the response on the same question from the 2000 survey which was 5.6 years. Over the last decade it appears more people chose to rent then own a home and lived longer in their current residence.

\subsection{Trip Characteristics}

Table 5 provides a comparison of point of origin from the three surveys. The most frequent point of origin for drivers headed west on I-580 was Tracy in all surveys. Trip characteristics changed little in 2019 from previous surveys' results. San Joaquin County continued to be the top point of origin in the three surveys, followed by Stanislaus Country. However, the percentage of commuters from San Joaquin County dropped from 71.2 percent in 2000 to 61.1 percent in 2019. Stanislaus County increased from 23.2 percent to 27.3 percent. Merced also increased from 0.8 percent to 2.5 percent. Some commuters began commuting against the traffic. Alameda commuters increased from 0.9 percent in 2000 to 6.5 percent in 2019. 
Table 5. Point of Origin

\begin{tabular}{cccc}
\hline Point of Origin & 2000 & 2006 & $2019-20$ \\
\hline San Joaquin County & $71.2 \%$ & $70.0 \%$ & $61.1 \%$ \\
Stanislaus County & $23.2 \%$ & $23.2 \%$ & $27.3 \%$ \\
Merced County & $0.8 \%$ & $0.8 \%$ & $2.5 \%$ \\
Contra Costa County & $1.4 \%$ & $0.5 \%$ & $1.3 \%$ \\
Alameda County & $0.9 \%$ & $2.4 \%$ & $6.5 \%$ \\
Other Counties & $2.5 \%$ & $3.1 \%$ & $1.3 \%$ \\
\hline
\end{tabular}

Table 6 reports a comparison of the top cities of point of origin for drivers from the 2000 and 2006 and 2019-20 surveys. The largest number of destinations reported by drivers using the I-580 were the cities of Livermore at $17.6 \%$ and Pleasanton at $14.7 \%$. The remaining trips ended in a variety of Bay Area destinations, including Oakland (8.2\%), San Jose (7.5\%), Hayward (6.4\%), Dublin (6.3\%), and Fremont (6.2\%). No other destination accounted for more than 5\% of the reported trips. On a county-by-county basis, $69.8 \%$ of the trips crossing the Altamont Pass ended in Alameda County and another $15.0 \%$ ended in Santa Clara County.

Table 6. Top Cities of Point of Destination

\begin{tabular}{cccc}
\hline Point of Origin & 2000 & 2006 & 2019 \\
\hline Alameda County & $59.8 \%$ & $69.8 \%$ & $51.8 \%$ \\
Livermore & $16.1 \%$ & $17.6 \%$ & $14.8 \%$ \\
Pleasanton & $14.0 \%$ & $14.7 \%$ & $11.2 \%$ \\
Oakland & $5.2 \%$ & $8.2 \%$ & $7.3 \%$ \\
Hayward & $5.8 \%$ & $6.4 \%$ & $3.7 \%$ \\
Fremont & $6.9 \%$ & $6.2 \%$ & $11.4 \%$ \\
Dublin & $4.0 \%$ & $6.3 \%$ & $3.4 \%$ \\
Santa Clara County & $21.6 \%$ & $15.0 \%$ & $22.3 \%$ \\
Contra Costa County & $7.5 \%$ & $6.7 \%$ & $3.8 \%$ \\
San Francisco & $3.4 \%$ & $3.3 \%$ & $14.8 \%$ \\
San Mateo & $3.3 \%$ & $2.8 \%$ & $3.6 \%$ \\
Other Counties & $5.0 \%$ & $2.4 \%$ & $3.7 \%$ \\
\hline
\end{tabular}

In all, $25.2 \%$ of the morning trips across the Altamont Pass comprises groups of two or more people in 2006. This is up from 2000, where only $14.3 \%$ of all trips were made by carpools of two or more people. Either commuters are commuting less or finding work in the NSJV. When asked "what is the primary purpose of our trip," 78.08 percent of the commuters responding to the survey reported "workplace related". There was continuous drop on a consistent basis to this response from the 2006 survey (90.1 percent) and 2000 survey ( 98 percent). This finding is consistent with 
the days of telecommuting increase in 2019 relative to the 2006 and 2000 surveys. On average, 50.08 percent of respondents made this trip three or more times a week. When compared to the previous survey done in 2006, the reported percentage for the same response was 65.1 percent which meant there was a drop of about 15 percent.

The overwhelming trip purpose in 2006 was "daily commute to/from work" at $84.6 \%$. Another $5.5 \%$ of all trips were related to work in some way, thus over $90.1 \%$ of the morning trips reported by commuters responding to the survey related to the workplace. On average, $65.1 \%$ of respondents made this trip four or more times a week. While these results show that trip purposes remained consistent in 2006, there was a slight decrease in the number of people traveling this corridor for work purposes. In $2000,98.0 \%$ of the morning trips were related to the workplace.

Table 7 reports the overall duration of commute per point of destination. ${ }^{16}$ The average time it takes to commute by auto remained the same at 1.34 hours, perhaps due to the increase in the number of people commuting over the years and due to those improvements made on roads to make commuting more efficient. On the positive side, average commuting time has not become longer over the years. The average time it takes to commute by bus is 2.08 hours. The average time travel by bus was reported to be 1.41 hours. This is an increase from the previous years by about 33 minutes. However, previous surveys qualify their findings by stating that travel times for bus and train riders do not necessarily include the time to reach the starting station and time to proceed from the ending station to the final destination.

Table 7. Duration of Trip per Point of Destination Overall

\begin{tabular}{cc}
\hline Point of Destination & Time in Hours \\
\hline Livermore & $1 \mathrm{~h} 9 \mathrm{~m}$ \\
Pleasanton & $1 \mathrm{~h} 7 \mathrm{~m}$ \\
Oakland & $1 \mathrm{~h} 15 \mathrm{~m}$ \\
Hayward & $2 \mathrm{~h}$ \\
Fremont & $1 \mathrm{~h} 30 \mathrm{~m}$ \\
Dublin & $1 \mathrm{~h} 37 \mathrm{~m}$ \\
San Francisco & $1 \mathrm{~h} \mathrm{57m}$ \\
\hline
\end{tabular}

In the 2019-20 survey, the average duration of commute by solo auto drivers is 1.26 hours. This finding was about ten minutes shorter than the finding in 2000 survey which reported 1.36 for the same category.

The survey conducted in 2000 reported that, on the average, 10.8 percent of Altamont Pass commuters work at home (telecommute) at least one day per week. There was a very notable 
increase in telecommuting response in the 2019-20 survey. When respondents were asked the same question, 64.8 percent reported that commuters work at home at least one day per week.

Previous surveys have reported results from several statistical analyses to fortify their findings. We repeat the same statistical analyses here to look for consistency with our aforementioned findings and with the prior surveys. Additionally, we extend our statistical analyses beyond the surveys done in 2000 and 2006 and conduct a set of probit estimations. These statistical estimations further allow us to look for additional clues and assess the robustness of our findings and further check for consistency with the previous studies. Figure 1 plots the association between length at current residence and the time the commute takes. A regression analysis of whether years have any predictive power on the commute time reveals that both the slope and intercept coefficients -.016 and 1.93, respectively were statistically significant at the conventional significance levels. The slope coefficient tends to be higher in absolute value than the estimations done in previous surveys. Such a finding is consistent with the view that as years at current residence increases there appears to lesser commute time of such respondents.

Figure 1. Years at Current Residence vs. Commute Time

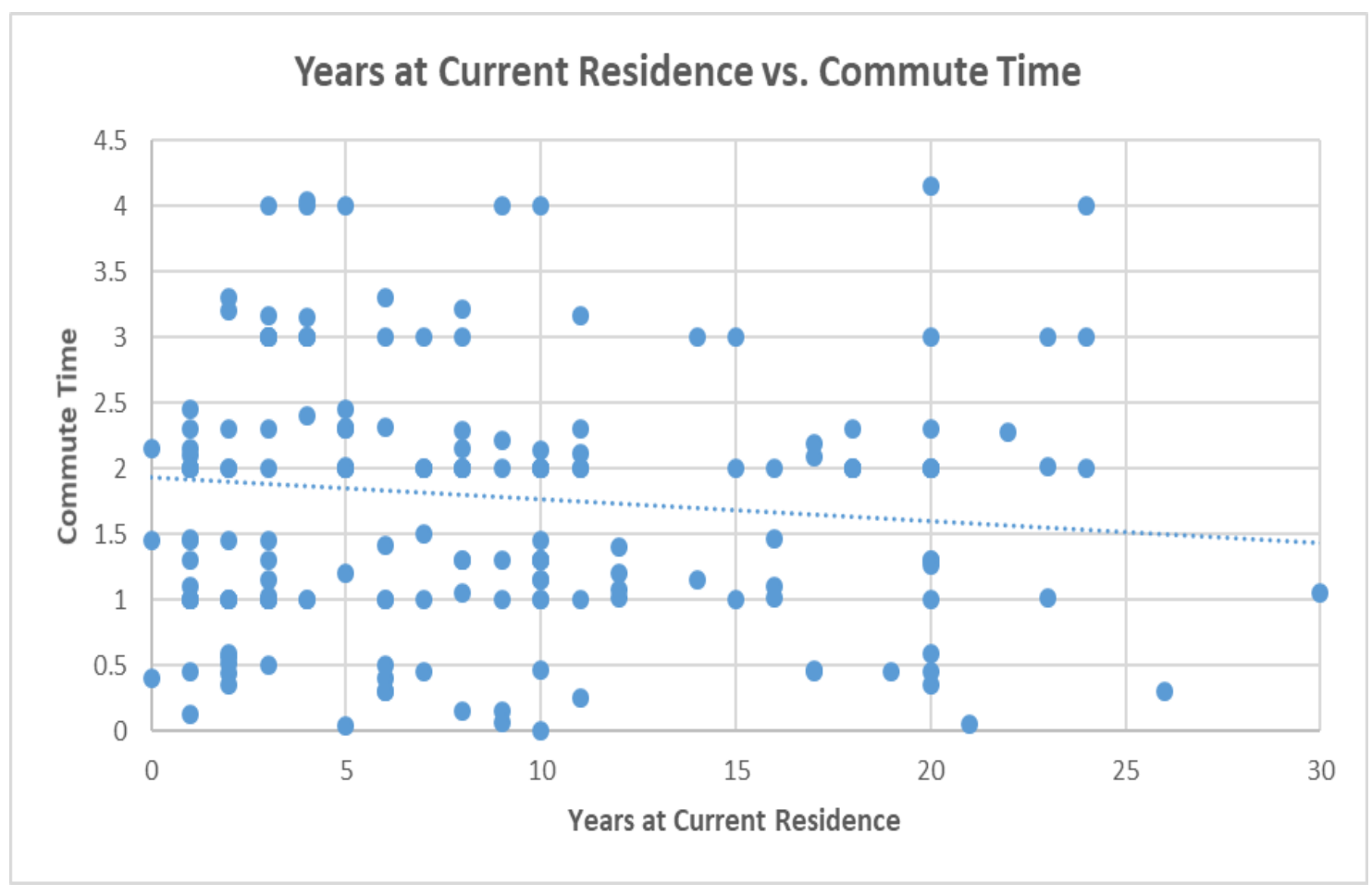

Out of pocket costs in the 2000 surveys pertain to parking fees, transit fares, vanpool expense, total driver costs, and composite commuter costs. The average parking fee reported in the 2000 survey was $\$ 7.14$ per day. In the 2019-20 survey, the out of pocket fee expense increased to $\$ 18.77$ per day. Considering the increases in the overall price levels and cost of real estate this number appears to be consistent. However, the overall increase in wages have been around 42 percent over a roughly 
twenty-year period. When this is factored in the account, it becomes apparent that parking fees have increased more than increase in wages over the twenty-year interval. In the 2000 survey, bus riders paid on average $\$ 6.15$ per day in fares, while train riders and BART riders spent $\$ 11.04$ and $\$ 9.11$, respectively. The respondents reported a combined average out-of-pocket costs of $\$ 16.94$ per day. When this fare is compared with the combined average cost of $\$ 8.76$, there appears to be roughly a two-fold increase over a period of two decades. This appears to be consistent with rate of inflation and wage increases over the same interval and slightly higher than the two measures of purchasing power. Vanpoolers reported average expenses of $\$ 9.52$ per day in the year 2000 survey. Respondents in the 2019-20 survey reported an average vanpool expense of $\$ 18.43$ per day. This finding is also consistent with the inflation rate and wage increase over the same time interval.

Table 8 reports the duration of trip per point of destination by bus. From Table 8 we find that the South San Francisco Bay area has a longer time compared with the East Bay area.

Table 8. Duration of Trip per Point of Destination by Bus

\begin{tabular}{cc}
\hline Point of Destination & Time in Hours \\
\hline Fremont & $2 \mathrm{~h} 15 \mathrm{~m}$ \\
Livermore & $2 \mathrm{~h} 26 \mathrm{~m}$ \\
Menlo Park & $2 \mathrm{~h} 10 \mathrm{~m}$ \\
San Mateo & $2 \mathrm{~h} 11 \mathrm{~m}$ \\
Pleasanton & $1 \mathrm{~h} 19 \mathrm{~m}$ \\
San Francisco & $2 \mathrm{~h}$ \\
San Jose & $2 \mathrm{~h} 40 \mathrm{~m}$ \\
San Ramon & $2 \mathrm{~h} 30 \mathrm{~m}$ \\
Santa Clara & $2 \mathrm{~h} \mathrm{30} \mathrm{m}$ \\
\hline
\end{tabular}

Table 9 reports the average time it takes to commute by train per city of destination. The overall average time to travel by train is two hours and nine minutes. In the year 2000 survey, on the other hand, the average commute time by train was two hours and one minute. Therefore, there was a trivial increase of about nine minutes in travel time by train from 2000 to 2019. 
Table 9. Duration of Trip per Point of Destination-Train Riders

\begin{tabular}{cc}
\hline Point of Origin & Time in Hours \\
\hline Livermore & $2 \mathrm{~h} 12 \mathrm{~m}$ \\
Pleasanton & $1 \mathrm{~h} 7 \mathrm{~m}$ \\
Oakland & $1 \mathrm{~h} 57 \mathrm{~m}$ \\
Hayward & $2 \mathrm{~h}$ \\
Fremont & $1 \mathrm{~h} 40 \mathrm{~m}$ \\
Dublin & $1 \mathrm{~h} 45 \mathrm{~m}$ \\
San Francisco & $1 \mathrm{~h} 57 \mathrm{~m}$ \\
Stockton & $3 \mathrm{~h}$ \\
Modesto & $1 \mathrm{~h} 7 \mathrm{~m}$ \\
\hline
\end{tabular}

Table 10 reports responses to the 2019-20 survey question, "Which of the following would encourage you to switch to carpooling?" While there was an overwhelming positive response to receiving cash incentives, those who favored tax incentives were less than half of the respondents who chose cash incentives. Noteworthy is the significant number of respondents, about 41.60 percent, who chose the option "not interested in carpooling at this time" despite the two incentives provided as selection options.

Table 10. Responses to the Question: Which of the following would encourage you to switch to carpooling?

\begin{tabular}{lc}
\hline Selected Choice & 2019 \\
\hline Cash incentive (e.g. rebates) & $41.33 \%$ \\
State tax incentive & $17.07 \%$ \\
Not interested in carpooling at this time & $41.60 \%$ \\
\hline
\end{tabular}

Table 11 reports responses to the 2019-20 survey question, "What would encourage you to ride the bus or the ACE train more often?" The highest percentage of respondents who prefer better transit connections between their home and ACE stations to choose public modes constitute 14.89 percent of the sample. The next highest-ranking response was having less expensive transit fares than at the current status. The third highest ranking selection at 5.34 percent was the AC trains/buses that offer more flexible hours. This result is also backed by respondents who chose $\mathrm{ACE}$ trains/buses that ran earlier and later in the morning, amounting to 4.20 percent and 4.39 percent, respectively. 
Table 11. Responses to the Question: What would encourage you to ride the bus or the ACE train more often?

\begin{tabular}{ll}
\hline Incentives & Percentages \\
\hline A program that would get me home or to a dependent in the event of an emergency if I & $2.48 \%$ \\
were traveling without my car & \\
ACE trains/buses that ran earlier in the evening & $0.95 \%$ \\
ACE trains/buses that ran earlier in the morning & $4.20 \%$ \\
ACE trains/buses that ran later in the evening & $1.72 \%$ \\
ACE trains/buses that ran later in the morning & $4.39 \%$ \\
Better transit connections between my home and ACE (which ACE station?) & $14.89 \%$ \\
Financial incentives to use alternatives & $2.48 \%$ \\
Less expensive transit fares & $7.44 \%$ \\
More flexible work hours & $5.34 \%$ \\
N/A, I always ride the bus or ACE & $7.82 \%$ \\
Other & $4.39 \%$ \\
Train or bus service from more cities & $2.29 \%$ \\
Train or bus service to more cities & $0.57 \%$ \\
\hline
\end{tabular}

Table 12 reports categorized responses to the open-ended question, "Please express your opinion(s) below on how to further improve commuting over Altamont Pass." The categories involve immediate, short-run, and long-run solutions. We define immediate solutions that can be adopted within a range of one year. Short-run solutions (following the economics definition) refers to keeping other inputs other than labor mainly constant or using the existing capital or infrastructure, whereas long-run is defined as all variables including capital usage vary significantly along with labor, such as construction of new freeways, adding new lanes and routes.

Table 12. Selected Responses to the Open-Ended Question: Please express your opinion(s) below on how to further improve commuting over Altamont Pass.

Selected List of Comments

\section{A. Immediate Solutions}

- $\quad \mathrm{ACE}$ trains/buses that ran later in the morning

- More trains midday and options to ride to Turlock area as well as Modesto

- Better regulation so it runs smoother.

- Train service directly from Stockton to Bay Area later at night.

- $\quad$ Fix the road more frequently and stop closing off lanes at $10 \mathrm{pm}$. Do road construction between $12 \mathrm{am}-5 \mathrm{am}$

- More reliable train transportations to be able to get less people driving on the road. Bart or Ace trains can help to alleviate traffic. ACE also needs more trains running throughout the day.

- $\quad$ More seats on ACE trains, and larger more efficient ACE train parking lots. 


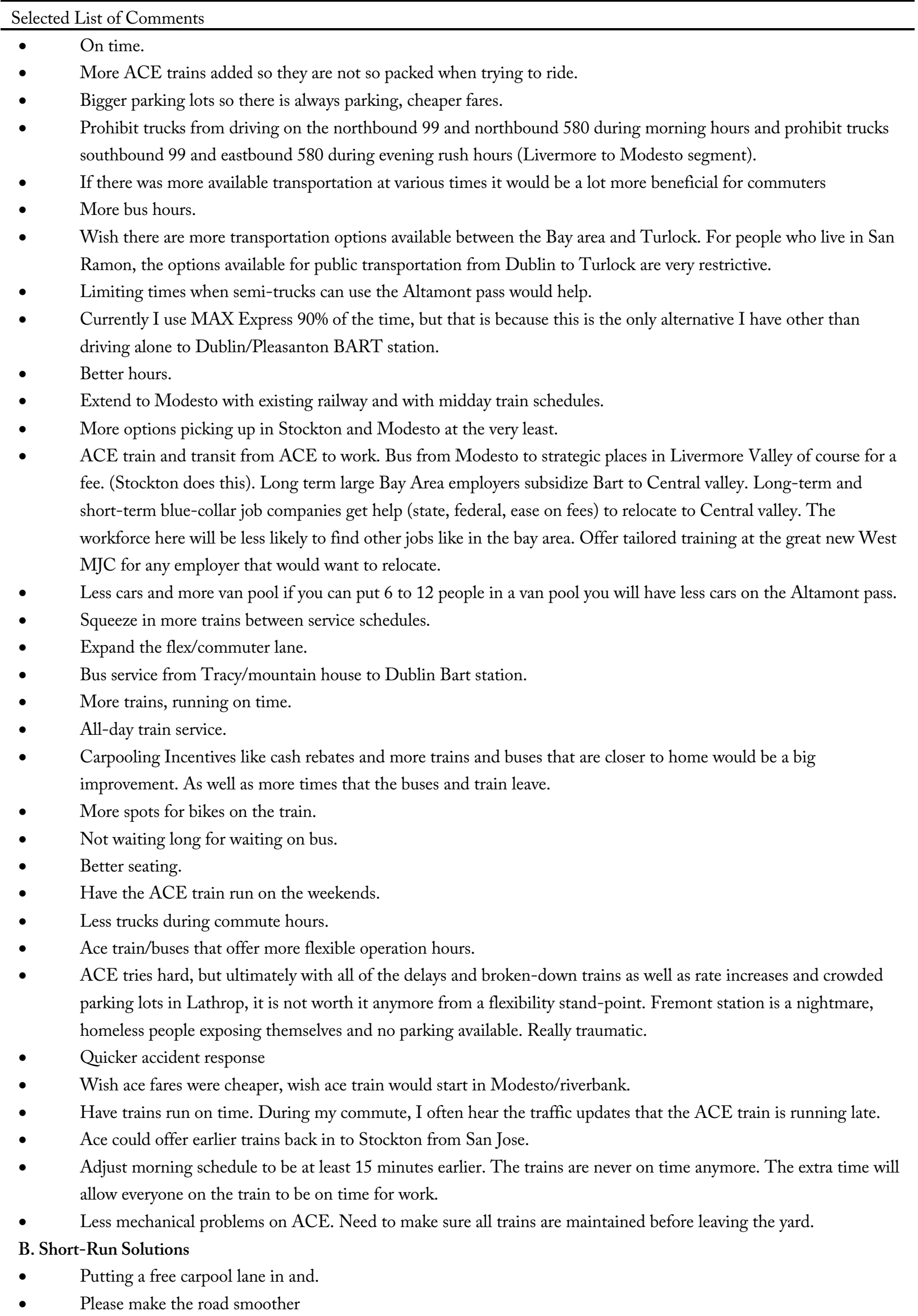




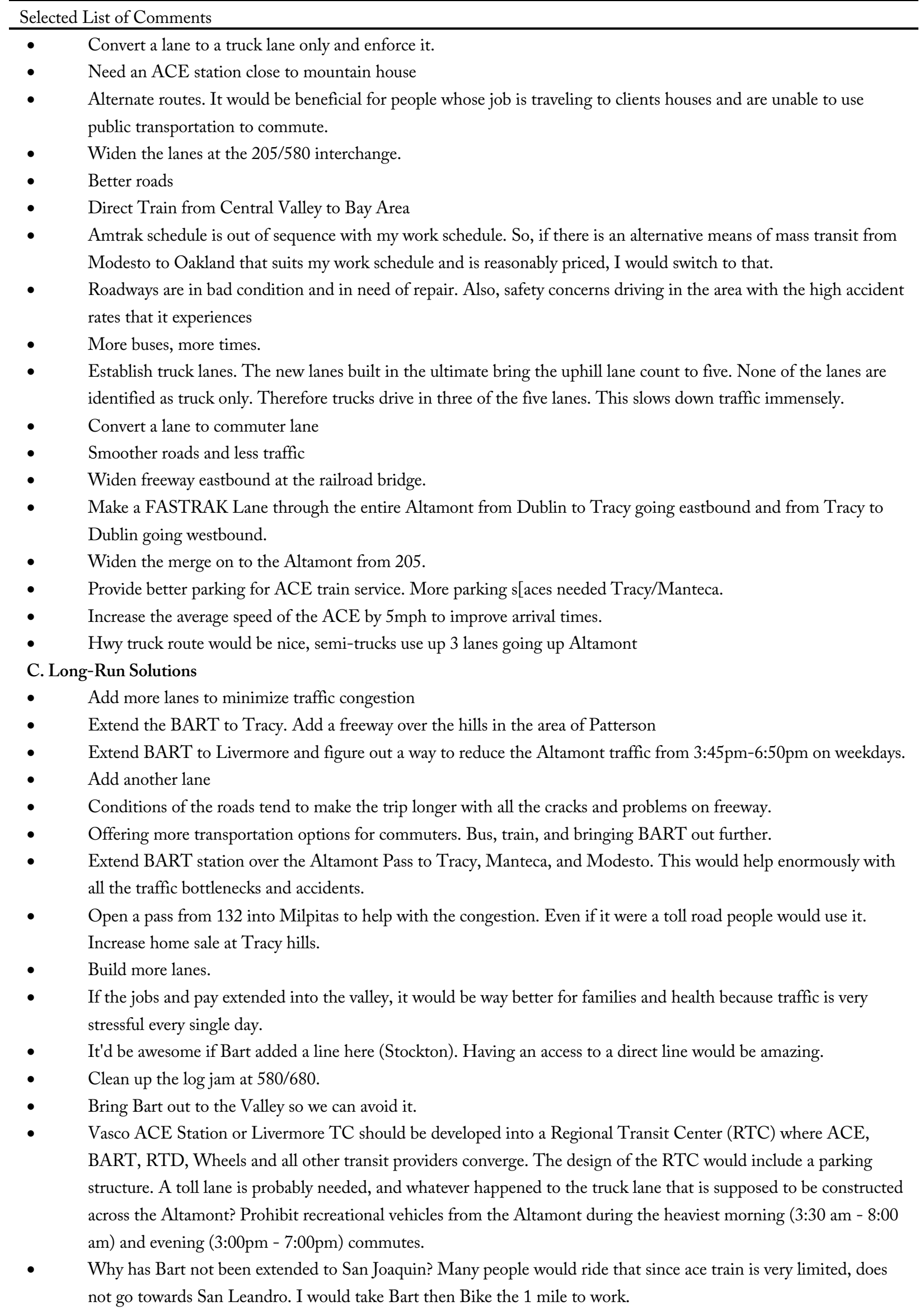




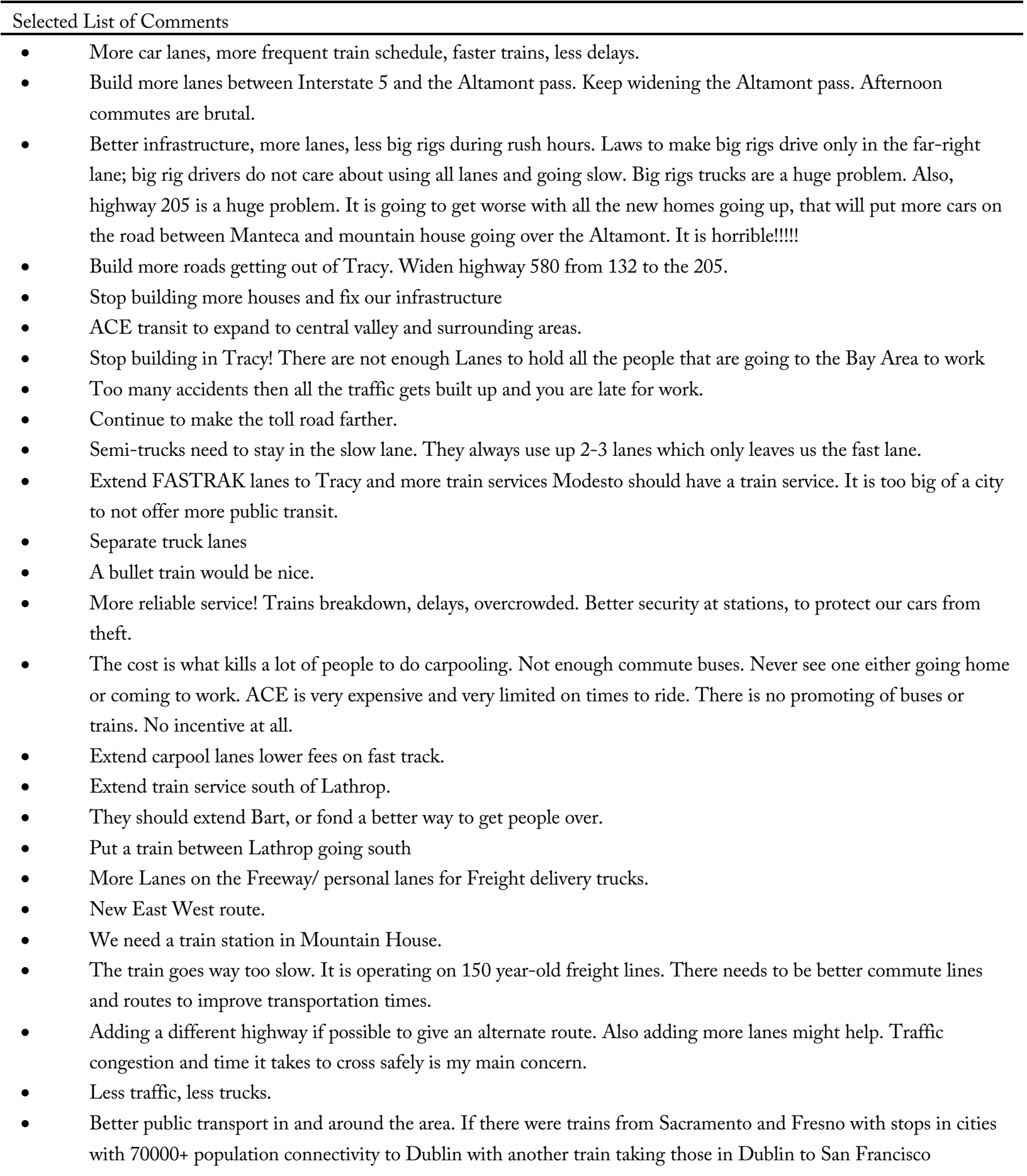

One such immediate solution that comes out of the study is limiting or providing incentives to minimize heavy truck traffic from getting on certain segments of 99 and 580 freeways during rush hour traffic, say the segment from Livermore to Modesto. This would mean northbound 99 and westbound 580 during morning hours and southbound 99 and eastbound 580 during evening hours when traffic is heaviest. It is a well-known fact that 99 freeway, if not the most, is one of the most 
dangerous freeways in the nation. There are few lanes and the lanes are narrow, carrying many semi-trucks transporting agricultural and manufactured products.

Our own measures during rush hour traffic show that limiting trucks similar to measures adopted for 580 freeway north of 238 freeway to Oakland would result in significant gains in efficiency in terms of money and time cost. Most importantly, because a significant number of accidents and breakdowns involve trucks, it would result in saving of many lives and injuries. For example, during rush hour, a single eighteen-wheel truck occupies the space of about three to four cars. According to our measurements on the freeways, in a one-mile range, there would be about eighteen to twenty trucks in the two of the three lanes. Similarly, there are about sixty to seventy cars in each lane. At the minimum, this would mean during rush hours that trucks generally occupy about thirty percent of the space cars would occupy. Eliminating heavy truck traffic for about one hour during rush hours would therefore correspond to almost adding one extra lane. The effect equivalent to adding one extra lane would naturally have a very significant positive impact on Altamont Pass commuters in terms of time and money cost.

Such a measure of limiting heavy truck traffic during rush hours would also benefit truck drivers who get paid per miles driven. Truck drivers who get stuck in bumper to bumper traffic significantly lose time and waste fuel relative to those who drive during smooth flowing traffic. Car drivers and truck drivers would be safer when there is significant decrease in traffic congestion.

There appears to be many immediate solutions that come out of our open-ended question from Table 12. These can be summarized as: improvements to provide free internet services in BART and $\mathrm{ACE}$ trains, providing vending machines, more comfortable seating to passengers, ${ }^{17}$ more flexible hours that run later in the mornings and earlier as well as later in the evenings, more bike spots on trains, better transit connections for ACE train commuters, and larger and more parking spaces that are efficient and solely converted to their use in stations such as Manteca. Immediate solutions would be a fast and efficient way to address the Altamont Pass commuting problems while working on short-run and long-run solutions that would take a longer time to address. These immediate solutions such as limiting truck traffic could significantly ease commuting during rush hours.

Short-run solutions that can be summarized from Table 12 are converting one lane of the existing freeways to a high-occupancy vehicle lane in the first stage and converting this lane to expressway in the second stage, particularly between Dublin and Tracy. A bus service from Tracy/Mountain House to Dublin BART station is needed as a fix that can be addressed in the short-run. Other requests can be summarized as: widen the freeway eastbound at railroad bridge, keep widening the Altamont Pass lanes, less delays in train schedules, more frequent trains, and less big rigs during rush hours. Some state that there is no easy way to get from Modesto to Livermore, citing this as a big obstacle to be resolved for Modesto commuters. Short-run solutions would be more costly to implement than immediate solutions, take a longer time to fix, and require more capital expenditures. Extending the expressway to Tracy appears to be a priority issue to address. 
Long-run solutions summarized from Table-12 are: extend the ACE train to Merced and extend BART to Livermore, perhaps in the first phase and then to Tracy in the second phase; add a station in Mountain House; provide alternate route; provide a big rig-only lane; and better regulation. Opening a pass from 132 to Milpitas and extending BART to Stockton are other suggestions. A few respondents request developing a Vasco ACE Station or a Livermore transit center into a Regional Transit Center where ACE, BART, RTD, and all other transit providers merge. The design of the RTC would include a parking structure.

There appear to be many complaints about semi-trucks needing to stay in the slow lane. Trucks appear to use too often two or even three lanes which leaves commuters only the fast lane. The city of Houston, Texas provides an example in figuring out how to widen lanes, and survey respondents want a similar approach to widen freeways in the Valley.

A few responses show a preference for train service to be extended south of Lathrop. The general opinion on trains are that they go way too slow, operating on 150 years old freight lines, underscoring the need to have better commute lines and routes to improve transportation times. Suggestions include increasing the average speed of the ACE by five miles per hour to improve arrival times and squeezing in more trains between schedules. There appears to be a strong sentiment for another East-West freeway to ease the traffic heading to the Silicon Valley. Such long-run solutions appear to be essential to address the growing population and housing and improve commuting to address growing demand in the region.

We continue our analysis to incorporate several statistical analyses using categorical variable models. As we indicate in our aforementioned discussions our purpose is to extend our analyses beyond the 2000 and 2006 survey studies and our empirical findings from statistical estimations serve as a basis for future studies to be done in the region. These results can then be used to compare statistical findings form our studies with the ones done in the future just like our study does with the 2000 and 2006 surveys.

In the 2019-20 survey, average years at current workplace is about 4.5 years for Altamont Pass commuters. Figure 2 plots the association between length at one's current workplace and the time it takes to commute. A regression analysis of whether work years have any association with commute time reveals that the slope value of .01 is not statistically significant while intercept value of 1.68 is statistically significant at the conventional significance levels. In future studies, a finding of higher slope coefficient would mean commuters who work longer at their current workplace are able to commute faster than in the past. Conversely, a lower coefficient would mean for those commuters who work longer at current workplace, commuting occurs at a slower speed than the past years. These results would naturally have important implications for the effectiveness of improvements made in the transportation network. Consequently, these estimations aim to provide a basis of comparison for future studies done on commute time and years at current workplace. 
Figure 2. Years at Current Employer vs. Commute Time

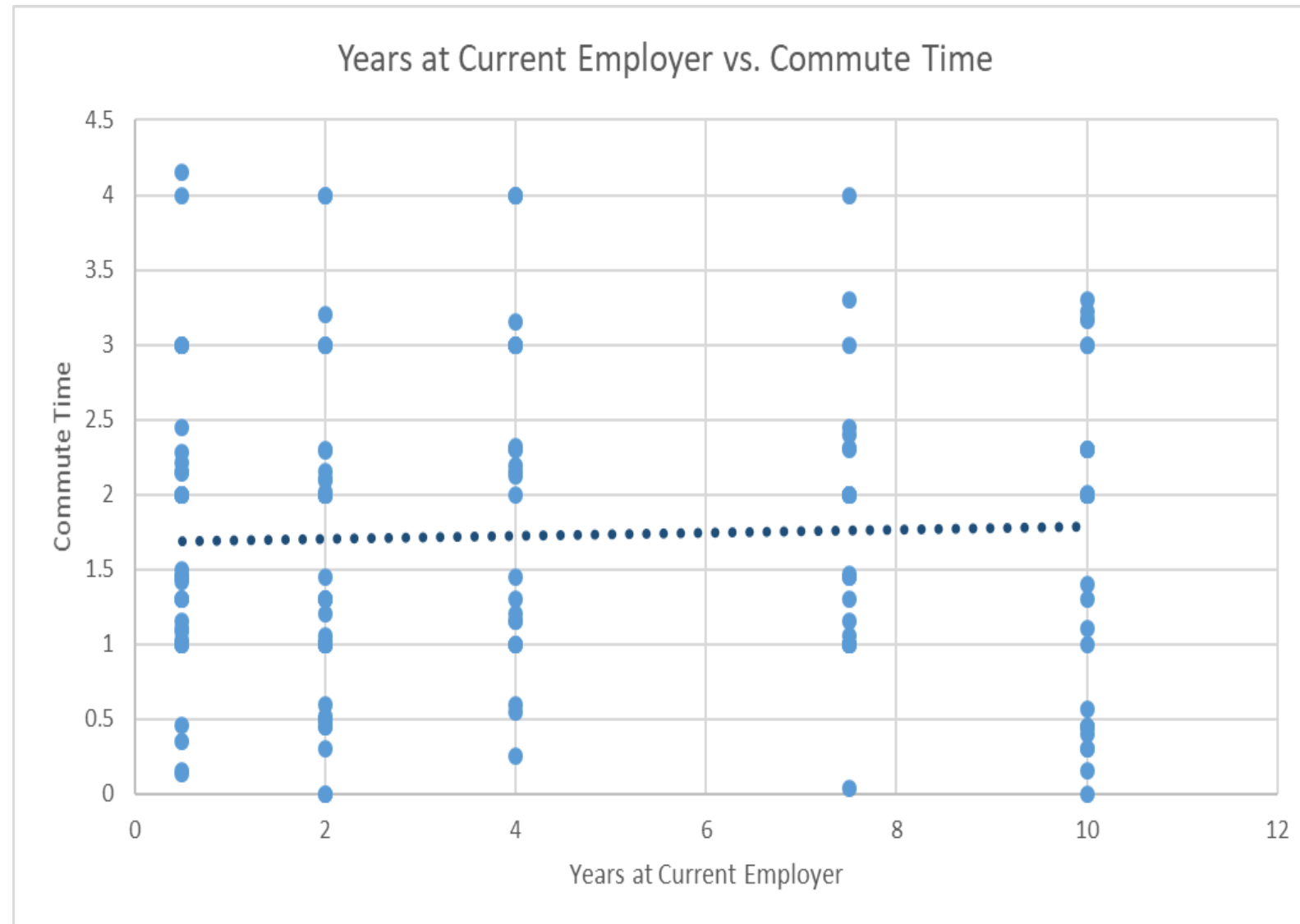

Figure 3 plots the association between age of respondents and commute time from the 2019-20 survey. A regression analysis of whether the postulated association between the two variables hold reveals that both the slope and intercept coefficients .010 and 1.19, are statistically significant at the conventional significance levels. The slope tends to be positive indicating that higher age is associated with longer commute time. In future studies, a higher coefficient estimate would mean older age is associated with longer commute hours. Conversely, a flatter trend than the finding there would mean higher ages are associated with shorter commute hours than before, thus providing evidence in favor of improvements in transportation network favoring the elderly. These estimations also aim to provide a basis of comparison for future studies done on age of commuters and commute time. 
Figure 3. Age vs. Commute Time

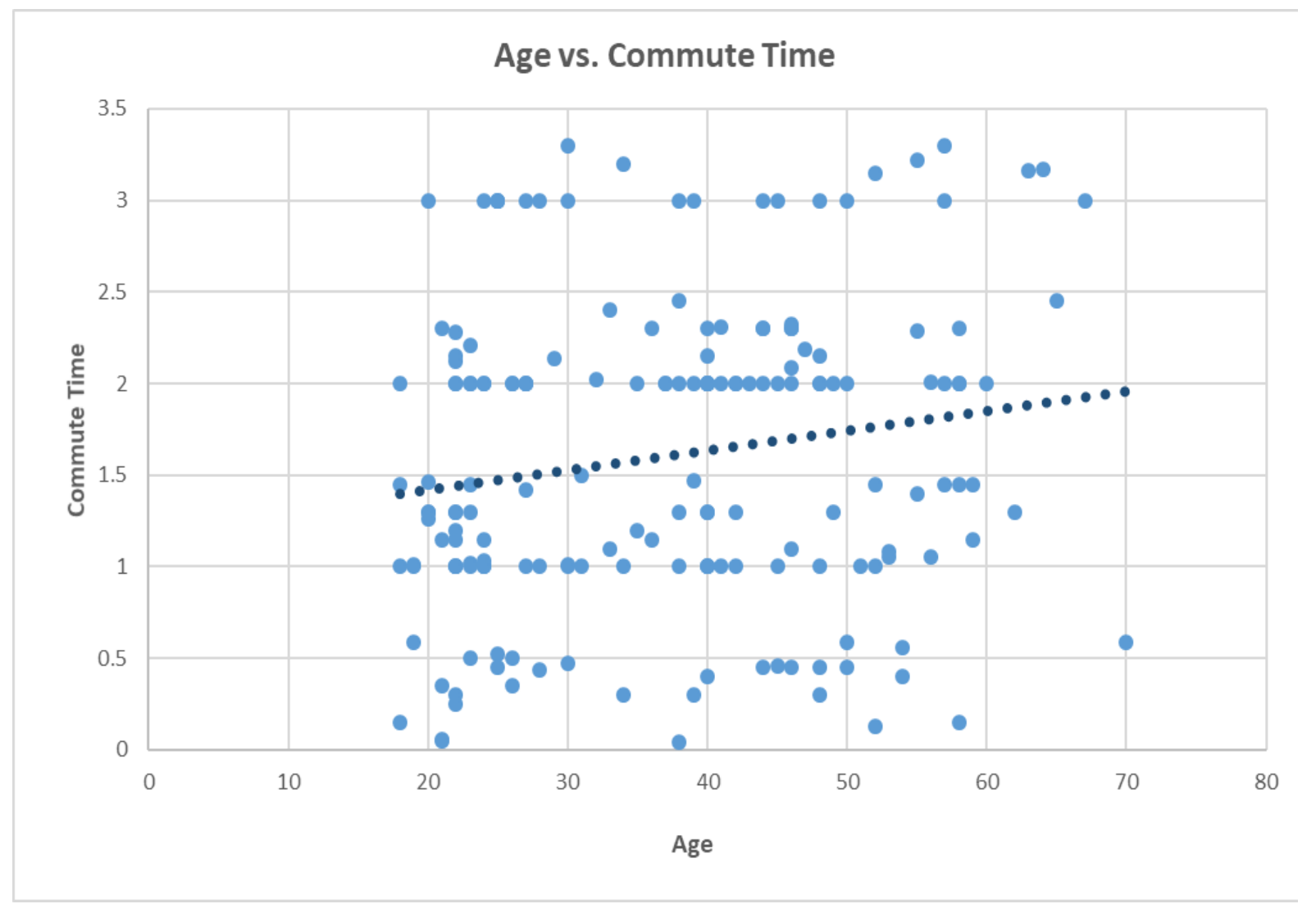

Average hourly salary for Altamont Pass Commuters is $\$ 30.11$ while highest salary is $\$ 68.91$ and lowest salary is $\$ 13.27$ based on the job classifications provided in 2019-20 survey. Figure 4 plots the association between hourly salary and commute time from the 2019-20 survey. A regression analysis of whether of the postulated association between the two variables holds reveals that while the slope coefficient of -.002 is not statistically significant, the intercept coefficient of 1.77 is at the conventional significance levels. The slope tends to be negative, consistent with the view that higher salary is associated with shorter commute time. This finding is also consistent with the view that higher income is spent on faster commute, such as purchasing faster vehicles or utilizing luxury transportation modes such as taxi and Uber rides. In future studies, a finding of lower coefficient estimate would mean older age is associated with even shorter commute hours. Conversely, a flatter trend would mean higher salary is associated with longer commute hours than found in this study. These estimations, similar to prior ones, aim to provide a basis of comparison for studies that follow the 2019-20 survey on salary and commute time. 
Figure 4. Hourly Salary vs. Commute Time

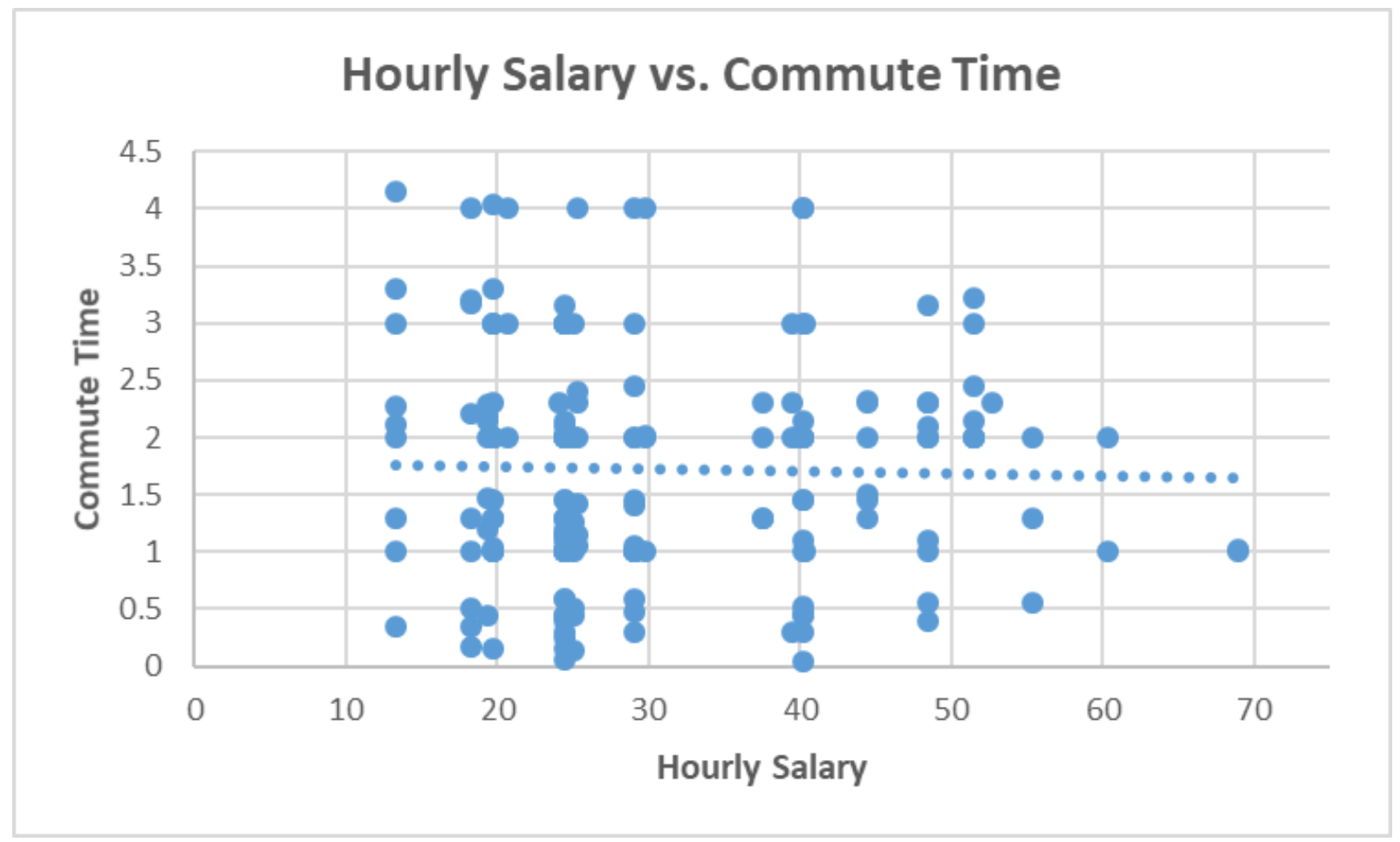

Table 13 reports educational characteristics of respondents answering the question, "Which of the following would encourage you to switch to carpooling?" The percentage of respondents with a doctorate degree who chose either cash incentive or tax incentive constituted 68.75 percent of the sample, while this percentage for respondents with a master's degree was 55.10 percent. Clearly, respondents with a master's degree were the cohort that chose a willingness to switch carpool the least given the cash and tax incentives. The cohort with 83.34 percent was the one that responded most favorably to cash and tax incentives, which was those who had high school degree as their highest educational attainment, consistent with the view that other factors such as age and income were also some other determinants to choosing the favorable answer of a preference towards cash and tax incentives to switch to carpooling. Those with a bachelor's degree constituted 63.88 percent while those with a technical degree constituted 68.23 percent in their category choosing cash and tax incentives as an encouraging factor to switch to carpooling. Respondents with an associate degree who chose cash and tax incentives to switch to carpooling made up 70.19 percent of the entire sample of respondents with an associate degree while those with same college degree made up 70.27 percent. The percentage of those respondents willing to switch to carpooling if they are provided a cash or tax incentive is mostly around three fourths of the sample in Table 3. Thus, based on these results, significant progress can be made in increasing carpooling numbers if commuters are offered some form of cash or tax incentive. 
Table 13. Educational Attainment of Respondents Answering the Question: Which of the following would encourage you to switch to carpooling?

\begin{tabular}{lc}
\hline Percentage of Combined Selection of Cash and Tax Incentive & 2019-20 Survey \\
\hline Doctorate degree & $68.75 \%$ \\
Master's degree & $55.10 \%$ \\
Bachelor's degree & $63.88 \%$ \\
Technical school & $69.23 \%$ \\
Associate degree & $70.19 \%$ \\
Some college & $70.27 \%$ \\
High school degree & $83.34 \%$ \\
\hline
\end{tabular}

Table 14 reports the average weekly salary of the respondents answering the question, "Which of the following would encourage you to switch to carpooling?" There appears to be no statistically significant difference among the options selected from the viewpoint of average salary. Those respondents who chose the cash incentive have an average weekly salary of $\$ 27.30$, while those who chose the state tax incentive have an average weekly salary of $\$ 29.72$. The respondents who selected "not interested in carpooling at this time" have an average salary of $\$ 29.69$, about the same as the other two selections. This finding is consistent with the view that choice of an incentive vs. no incentive is not associated with income. The willingness to switch to carpooling based on cash or state tax incentive appears to be more related to personal preference.

Table 14. Average Weekly Salary of the Respondents Answering the Question: Which of the following would encourage you to switch to carpooling?

\begin{tabular}{lc}
\hline Selected Choice & 2019 Average Weekly Salary \\
\hline Cash incentive (e.g. rebates) & $\$ 27.30$ \\
State tax incentive & $\$ 29.72$ \\
Not interested in carpooling at this time & $\$ 29.69$ \\
\hline
\end{tabular}

Table 15 reports average commute time of respondents answering the question, "Which of the following would encourage you to switch to carpooling?" There appears to be no statistically significant difference among the options selected from the viewpoint of commute time. However, those respondents who chose a state tax incentive have a longer average commute time of two hours and seven minutes which is about twenty minutes longer than the other two selections. This finding is consistent with the view that choice of an incentive versus no incentive is not associated with longer or shorter commute time. The willingness to switch to carpooling based on cash or state tax incentive from this standpoint also appears to be more related to personal preference. 
Table 15. Average Commute Time Based the Question: Which of the following would encourage you to switch to carpooling?

\begin{tabular}{lc}
\hline Selected Choice & Average Commute Time \\
\hline Cash incentive (e.g. rebates) & 1 hour and 49 minutes \\
State tax incentive & 2 hours and 07 minutes \\
Not interested in carpooling at this time & 1 hour and 47 minutes \\
\hline
\end{tabular}

\section{Summary \& Conclusions}

In this study, we conducted a survey of Altamont Commuters and compared results with the results from similar surveys done in previous years. In particular, we investigated whether there were any changes in commuters' perceptions and behavior longitudinally. We examined responses from same three counties, San Joaquin, Stanislaus and Merced.

Two surveys were conducted in prior years. One was conducted in 2000 and the other was conducted in 2006. Our 2019-2020 survey compares the results against the ones that were done in 2000 and 2006 to investigate the extent of change that have occurred in commuter perceptions and behavior. The survey responses show that while there were significant changes that have occurred in some questions, there were minimal or qualitatively no change in other questions.

One of the most noteworthy responses that stands out relative to others was that ACE trains schedules are not in sync with commuters' work patterns. According to respondents' feedback, those that leave in the morning are stuck all day and wait until the evening to get back home. Commuters want more flexible hours and trains that run throughout the day or, at the minimal, during midday and during earlier hours in the morning and later hours in the evening. Even if this means operating at a loss for several months for ACE trains in terms of costs versus revenues, it is imperative that $\mathrm{ACE}$ trains offer more flexible hours to significantly encourage public transportation among Altamont Pass commuters.

Another striking response that come out of the survey is limiting heavy trucks from getting on freeways during rush hour traffic. It is a well-known fact that the 99 freeway, if not the most, is one of the most dangerous freeways in the nation. There are few lanes and the lanes are narrow, carrying many trucks transporting agricultural and manufactured products. Respondents' complaints center on their safety on the road, time cost, and money cost. Respondents note that a significant number of accidents actually involve trucks completely blocking lanes and posing danger to their safety on the roads. Semi-trucks block two out of three lanes, greatly slowing traffic. 
This in turn corresponds to longer times spent on roads, say covering roughly a 35-mile distance in about 70 minutes, as well as higher costs of commuting resulting from loss of fuel efficiency. Solutions proposed were prohibiting trucks getting on freeways similar to a measure used for 580 freeway north of 238 freeway, providing incentives or restrictions for truck drivers to stay off the freeways during rush hours. Considering that truck drivers get paid by per mile driven, getting stuck in traffic means loss of revenue and time for them as well.

Providing more freedom such as bike spaces in BART and other trains, snacks and drinks from vending machines, free internet services, more comfortable seating, and charge ports are other frequently requested items in the survey. Extension of BART to Livermore and then Tracy is another frequently mentioned response along with more efficient bus and train links to BART. Wider parking spaces and more efficient parking solely assigned to commuters and prevention of car thefts are other requested changes.

The feedback received from the open-ended question in Table 12 can be categorized as immediate, short-run, and long-run solutions. Immediate solutions range from providing more flexible hours for trains and buses that extend throughout the day and weekends, and limiting semi-trucks from getting on freeways during the rush hours to improve safety of commuters and increase efficiency of time spent in commuting and cost of commuting. Short-term solutions range from adding an HOV lane and later an expressway that extends to Tracy to measures to relieve congestion areas such as widening the railway bridge after passing Altamont Pass eastward, lowering ACE, BART and bus fees to encourage more commuters to use public mode, and providing cash incentives and tax breaks to lower the time and money cost of commuting and hence make commuting more viable. Long-term solutions involve adding more lanes, widening the existing lanes, providing a truck route over the Altamont Pass, and adding more train routes from the Valley to the Bay Area to alleviate the future congestion coming from building more homes inland particularly in areas such as Tracy which does not currently have the infrastructure to sustain the influx of population.

In all, the 2019-20 survey reveals many new options that can be adopted immediately, in the shortrun, and in the long-run to improve commuting experience of Altamont Pass commuters who are willing to change their behavior if their voices are heard and improvements are made in accordance with their suggestions. 


\section{Appendix: Regional Map}

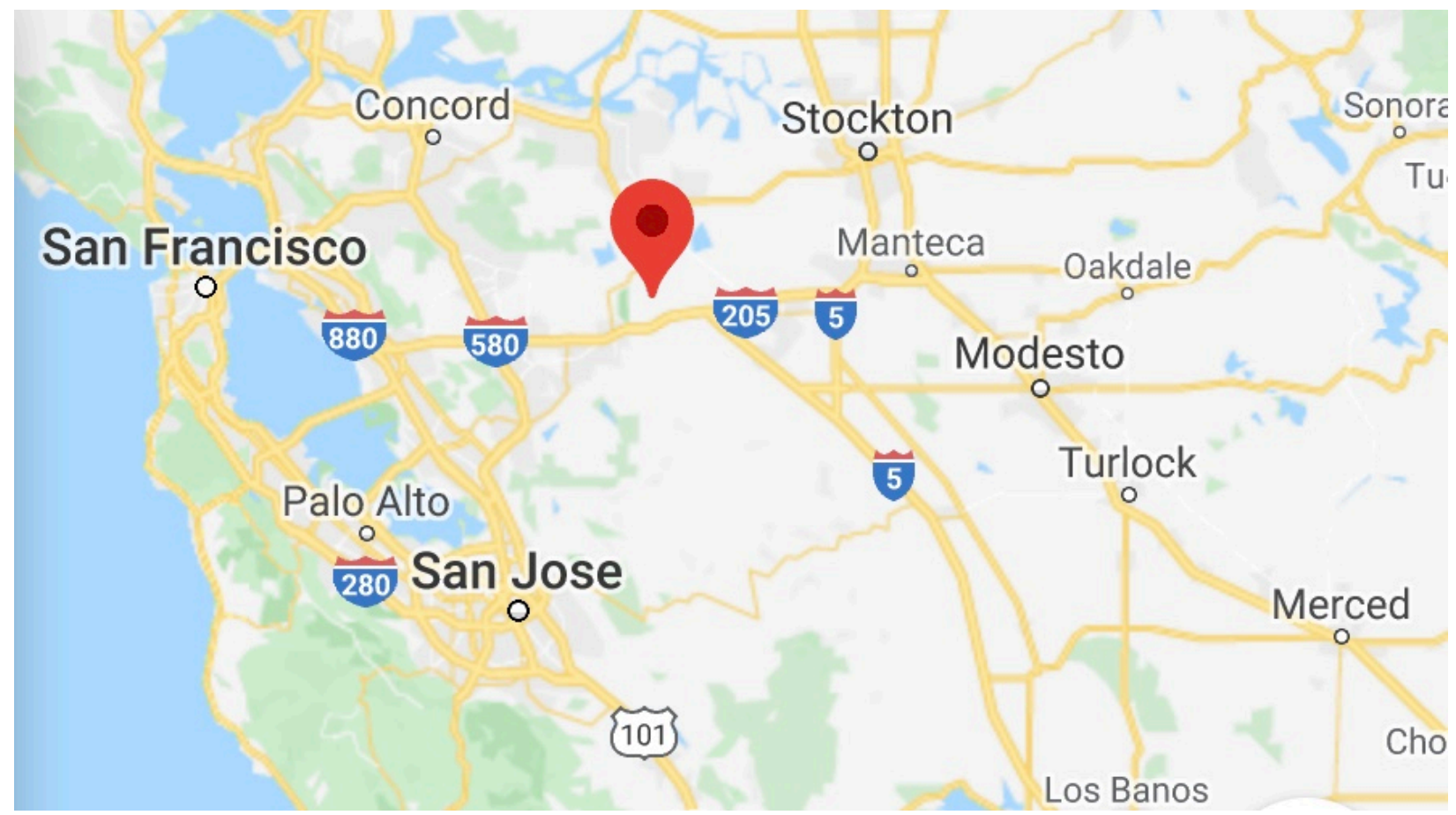

Source: Google Maps.

*The pinned location marks the location of Altamont Pass. 


\section{Endnotes}

${ }^{1}$ Billheimer, John W. and McNally, Juliet. (2000). Altamont Pass Commuter Survey; Yosemite Computer Consultants \& Wright, Jim. (2003). Analysis of the 2003 Altamont Pass Commuter Survey

${ }^{2}$ San Joaquin Council of Governments (2006). Altamont Pass Commuter Study; Bennet, Sydney. (2018, May 25).

${ }^{3}$ Altamont Pass traffic is unique in that it has both heavy truck traffic presence and high density of traffic of any kind during rush hours. This is because the region is heavily agricultural thus many trucks carrying manufactured and agricultural goods use the roads for delivery.

${ }^{4}$ Please refer to the map provided in the Appendix.

5 "Rise of the Super Commuters," Sydney Bennet, May 25, 2018, https://www.apartmentlist.com/rentonomics/increase-in-long-super-commutes/.

${ }^{6}$ Gerber, Philippe, Ahmed El-Geneidy, Kevin Manaugh, and Sébastien Lord, "From Workplace Attachment to Commuter Satisfaction Before and After a Workplace Relocation," Transportation Research Part F: Traffic Psychology and Behaviour 71 (2020): 168-181. https://doi.org/10.1016/j.trf.2020.03.022.

${ }^{7}$ Ghimire, Ramesh, and Colby Lancelin, "The Relationship Between Financial Incentives Provided by Employers and Commuters' Decision to Use Transit: Results From the Atlanta Regional Household Travel Survey," Transport Policy 74 (2019): 103-113.

https://doi.org/10.1016/j.tranpol.2018.11.005

${ }^{8}$ Zhang, Zheng, Hidemichi Fujii, and Shunsuke Managi, "How Does Commuting Behavior Change Due to Incentives? An Empirical Study of the Beijing Subway System," Transportation Research Part F: Traffic Psychology and Behaviour 24 (2014): 17-26.

https://doi.org/10.1016/j.trf.2014.02.009.

${ }^{9}$ Jang, Jaemin, and Joonho Ko, "Factors Associated with Commuter Satisfaction Across Travel Time Ranges," Transportation Research Part F: Traffic Psychology and Behaviour 66 (2019): 393405. https://doi.org/10.1016/j.trf.2019.09.019.

${ }^{10}$ Shin, Eun Jin, "Commuter Benefits Programs: Impacts on Mode Choice, VMT, and Spillover Effects," Transport Policy 94 (2020): 11-22. https://doi.org/10.1016/j.tranpol.2020.05.001.

${ }^{11}$ Shaheen, Susan A., Nelson D. Chan, and Teresa Gaynor, "Casual Carpooling in the San Francisco Bay Area: Understanding User Characteristics, Behaviors, and Motivations," Transport Policy 51 (2016): 165-173. https://doi.org/10.1016/j.tranpol.2016.01.003.I

${ }^{12}$ The 2019-20 survey refers to the present survey conducted in this study. 
${ }^{13}$ Norusis, Marija J, SPSS for Windows: Base System User's Guide, Release 6.0 (Chicago, IL: SPSS Incorporated, 1993).

${ }^{14}$ Doan, Thomas A. (1988). Regression Analysis of Time Series. Release 8.0. Estima Incorporated.

${ }^{15}$ Hall, Robert, Eviews (Release 11; Windows, Irvine, CA: IHS Global Incorporated, 1994).

Snow, Jonathan, and Marcilyn Mann, Qualtrics Survey Software: Handbook for Research Professionals (Provo, UT: Qualtrics Labs, 2013).

${ }^{16}$ Times reported here are reflective of total time of the journey and may include multi-mode transportation. We do not exclude first-mile and last-mile time data.

${ }^{17}$ Providing internet services in trains may have already started by the time this report is finalized. 


\section{Bibliography}

Bennet, Sydney. "Rise of the Super Commuters." Retrieved May 8, 2020.

https://www.apartmentlist.com/rentonomics/increase-in-long-super-commutes

Billheimer, John W. \& McNally, Juliet. (2000). Altamont Pass Commuter Survey.

Doan, Thomas A. (1988). Regression Analysis of Time Series. Release 8.0. Estima Incorporated.

Gerber, Philippe, Ahmed El-Geneidy, Kevin Manaugh, and Sébastien Lord. "From Workplace Attachment to Commuter Satisfaction Before and After a Workplace Relocation." Transportation Research Part F: Traffic Psychology and Behaviour 71 (2020): 168-181. https://doi.org/10.1016/j.trf.2020.03.022.

Ghimire, Ramesh, and Colby Lancelin. "The Relationship Between Financial Incentives Provided by Employers and Commuters' Decision to Use Transit: Results From the Atlanta Regional Household Travel Survey." Transport Policy 74 (2019): 103-113. https://doi.org/10.1016/j.tranpol.2018.11.005.

Hall, Robert. Eviews (Release 11). Windows. Irvine, CA: IHS Global Incorporated, 1994.

Jang, Jaemin, and Joonho Ko. "Factors Associated with Commuter Satisfaction Across Travel Time Ranges." Transportation Research Part F: Traffic Psychology and Behaviour 66 (2019): 393-405. https://doi.org/10.1016/j.trf.2019.09.019.

Norusis, Marija J. SPSS for Windows: Base System User's Guide, Release 6.0. Chicago, IL: SPSS Incorporated, 1993.

San Joaquin Council of Governments (2006). Altamont Pass Commuter Study.

Shaheen, Susan A., Nelson D. Chan, and Teresa Gaynor. "Casual Carpooling in the San Francisco Bay Area: Understanding User Characteristics, Behaviors, and Motivations." Transport Policy 51 (2016): 165-173. DOI: 10.1016/j.tranpol.2016.01.003.

Shin, Eun Jin. "Commuter Benefits Programs: Impacts on Mode Choice, VMT, and Spillover Effects." Transport Policy 94 (2020): 11-22.

https://doi.org/10.1016/j.tranpol.2020.05.001.

Snow, Jonathan, and Marcilyn Mann. Qualtrics Survey Software: Handbook for Research Professionals. Provo, UT: Qualtrics Labs, 2013.

Yosemite Computer Consultants and Jim Wright. (2003). Analysis of the 2003 Altamont Pass Commuter Survey. 
Zhang, Zheng, Hidemichi Fujii, and Shunsuke Managi. "How Does Commuting Behavior Change Due to Incentives? An Empirical Study of the Beijing Subway System." Transportation Research Part F: Traffic Psychology and Behaviour 24 (2014): 17-26. https://doi.org/10.1016/j.trf.2014.02.009. 


\section{About the Authors}

\section{Gökçe Soydemir}

Gökçe Soydemir (Ph.D., M.Phil.) is the principle Investigator in this project. Dr. Gökçe Soydemir currently works as the Foster Farms Endowed Chair of Business Economics and Professor of Finance and Economics at California State University, Stanislaus. He has over forty publications in quality peer reviewed journals. Dr. Soydemir supervises a university-wide forecasting team to publish the San Joaquin Valley Business Forecast Report, a bi-annual publication of California State University, Stanislaus. The report has appeared more than hundred times in popular media and personal blogs and has been inquired about by Congressional Quarterly from Washington D.C. He teaches both undergraduate and graduate courses in finance and economics. His research interests include applied econometrics, regional economics, business, economic forecasting, and international finance. Dr. Soydemir has previously obtained grants from institutions such as San Francisco Public Utilities Commission, The Communications Institute in Los Angeles, Pacific Gas and Electric, and Chicago Board of Exchange.

\section{Orestis Panos Panagopoulos}

Orestis Panos Panagopoulos (Ph.D.) is the co-investigator in this project. Dr. Orestis Panos Panagopoulos earned his Diploma in Production Engineering and Management from the Technical University of Crete. He received his M.Sc. in Industrial and Systems Engineering from the University of Florida. He earned his Ph.D. in Industrial Engineering and Management Systems from the University of Central Florida. His focus is on big data analytics, data mining, and machine learning. He specializes in massive datasets, feature selection and dimensionality reduction techniques, and robust data mining. Panagopoulos' research has been funded through grants received from public organizations and the private sector. His work has been published in journals such as Omega, Expert Systems with Applications, and others.

\section{Xun Xu}

$\mathrm{Xun} \mathrm{Xu}$ (Ph.D.) is the co-investigator in this project. Xun $\mathrm{Xu}$ holds a $\mathrm{PhD}$ in Operations Management from the Washington State University. He is currently an Associate Professor in the Department of Management, Operations, and Marketing in College of Business Administration at the California State University, Stanislaus, in the United States. He teaches operations management and management science-related courses. His research interests include service operations management, supply chain management and coordination, sustainability, e-commerce, data and text mining, and hospitality and tourism management. He has published over 30 papers on such journals as Annals of Tourism Research, Computers and Industrial Engineering, Decision Support Systems, European Journal of Operational Research, Journal of Business Research, Journal of the 
Operational Research Society, Journal of Travel Research, International Journal of Hospitality Management, International Journal of Contemporary Hospitality Management, International Journal of Information Management, International Journal of Production Economics, International Journal of Production Research, along with others. 


\section{Hon. Norman Y. Mineta}

\section{MTI BOARD OF TRUSTEES}

Founder, Honorable Norman

Mineta*

Secretary (ret.),

US Department of Transportation

Chair,

Abbas Mohaddes

President \& COO

Econolite Group Inc.

Vice Chair,

Will Kempton

Executive Director

Sacramento Transportation Authority

Executive Director,

Karen Philbrick, PhD*

Mineta Transportation Institute

San José State University

Winsome Bowen

Chief Regional Transportation

Strategy

Facebook

David Castagnetti

Co-Founder

Mehlman Castagnetti

Rosen \&Thomas

\section{Maria Cino}

Vice President

America \& U.S. Government

Relations Hewlett-Packard

Enterprise

\author{
Grace Crunican** \\ Owner \\ Crunican LLC
}

Donna DeMartino

Managing Director

Los Angeles-San Diego-San Luis

Obispo Rail Corridor Agency

Nuria Fernandez**

General Manager \& CEO

Santa Clara Valley Transportation

Authority (VTA)

\section{John Flaherty}

Senior Fellow

Silicon Valley American

Leadership Form

William Flynn *

President \& CEO

Amtrak

Rose Guilbault

Board Member

Peninsula Corridor

Joint Powers Board

Ian Jefferies*

President \& CEO

Association of American

Railroads
Diane Woodend Jones

Principal \& Chair of Board

Lea + Elliott, Inc.

David S. Kim*

Secretary

California State Transportation

Agency (CALSTA)

Therese McMillan

Executive Director

Metropolitan Transportation

Commission (MTC)

Bradley Mims

President \& CEO

Conference of Minority

Transportation Officials

(COMTO)

Jeff Morales

Managing Principal

InfraStrategies, LLC

Dan Moshavi, PhD*

Dean, Lucas College and Graduate

School of Business

San José State University

Toks Omishakin*

Director

California Department of

Transportation (Caltrans)
Takayoshi Oshima

Chairman \& CEO

Allied Telesis, Inc.

Paul Skoutelas*

President \& CEO

American Public Transportation

Association (APTA)

Beverley Swaim-Staley

President

Union Station Redevelopment

Corporation

Jim Tymon*

Executive Director

American Association of

State Highway and

Transportation Officials

(AASHTO)

Larry Willis*

President

Transportation Trades

Dept.,AFL-CIO

* = Ex-Officio

${ }^{* *}=$ Past Chair, Board of Trustees

\section{Directors}

Karen Philbrick, PhD

Executive Director

Hilary Nixon, PhD

Deputy Executive Director

Asha Weinstein Agrawal, PhD

Education Director

National Transportation Finance

Center Director

\section{Brian Michael Jenkins}

National Transportation Security

Center Director

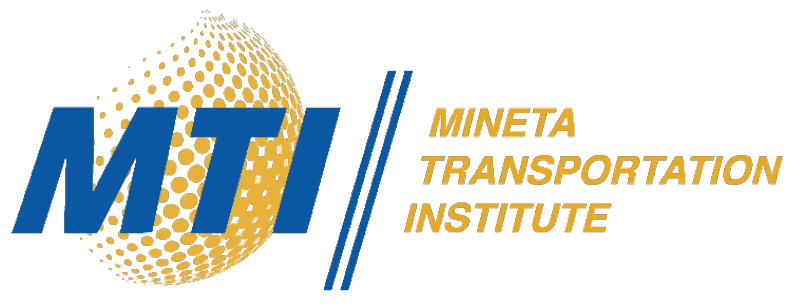

